COO-1198-1155

\title{
ANNUAL PROGRESS REPORT
}

The Science of Materials

Contract AT(11-1)-1198

Submitted to the

ENERGY RESEARCH AND DEVELOPMENT ADMINISTRATION

by the

MATERIALS RESEARCH LABORATORY

UNIVERSITY OF ILLINOIS

URBANA, ILLINOIS

March 1975 


\section{DISCLAIMER}

This report was prepared as an account of work sponsored by an agency of the United States Government. Neither the United States Government nor any agency Thereof, nor any of their employees, makes any warranty, express or implied, or assumes any legal liability or responsibility for the accuracy, completeness, or usefulness of any information, apparatus, product, or process disclosed, or represents that its use would not infringe privately owned rights. Reference herein to any specific commercial product, process, or service by trade name, trademark, manufacturer, or otherwise does not necessarily constitute or imply its endorsement, recommendation, or favoring by the United States Government or any agency thereof. The views and opinions of authors expressed herein do not necessarily state or reflect those of the United States Government or any agency thereof. 


\section{DISCLAIMER}

Portions of this document may be illegible in electronic image products. Images are produced from the best available original document. 
INTRODUCTION

SIGNIFICANT RESULTS

LIST OF PROJECT TITLES AND PRINCIPAL INVESTIGATORS

PROJECT REPORTS

Metallurgy and Ceramics

NT-03-01-01-0 Structure of Materials . . 。 . . 。 . 19

Paul A. Beck . . . . . . . . . . . 19



C. Marvin Nayman 。. . . . . . . . 24

NT-03-01-02-0 Mechanical Properties .. . . . . . . 29

Howard K. Birnbaum . . . . . . . . 29

Harish L. Fraser . . . . . . . . . . . 31

Marvin Metzger 。 . . . . . . . . . . 33

E. Neville Pugh . . . . . . . . . . 35

Charles Ao Wert . . . . . . . . . 38

NT-03-01-03-0 Physical Froperties . . . . . . . . 41

Carl J. Altstetter . . . . . . . . . 41

Theodore JoRowland . . . . . . . 443

Solid State Physics

NT-03-02-02-0 Experimental Research . . . . . . 45

Harry G. Drickamer . . . . . . . . ०45

Andrew V。Granato . . . . . . . . 49

David Lazarus . • • • • . . . . . 51

Ralph 0. Simmons 。. . . . . . . . 53

Charles $\mathrm{P}_{0}$ Slichter . . . . . . . . 55

Wende1l S. Williams $. . \circ . \circ . . .61$

NT-03-02-04-0 Particle-Solid Interactions . . . . . . 65

James S. Koehler 。. . . . . . .65

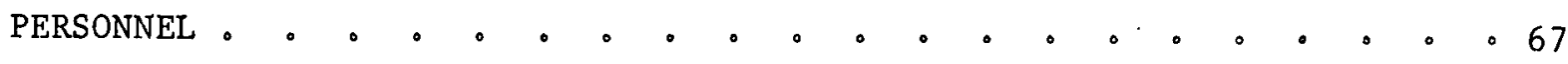

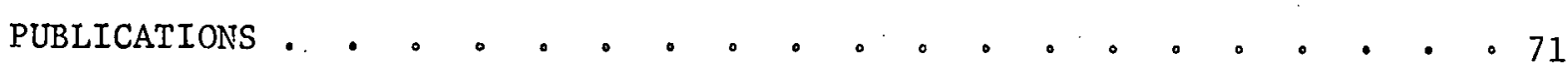

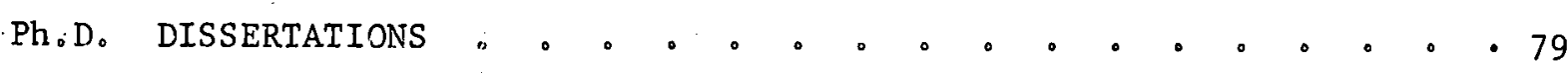

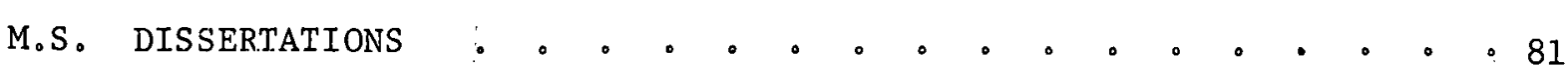




\section{INTRODUCTION}

The Materials Research Laboratory of the University of Illinois was established in june 1962 as an interdepartmental and interdisciplinary laboratory of the College of Engineering. The following departments of the University participate in its operation:

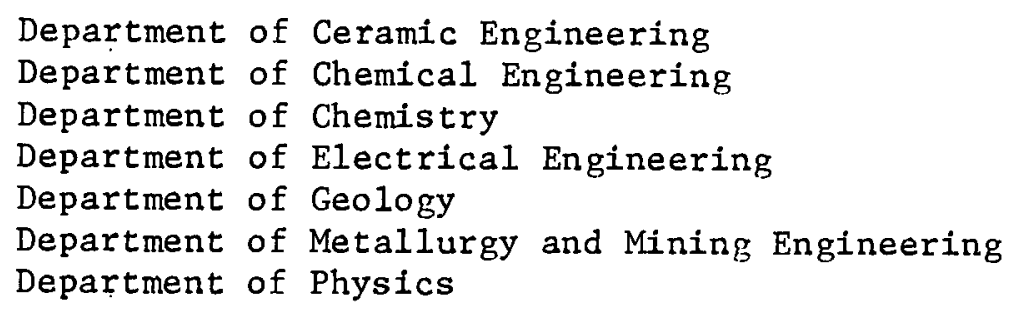

The administration of the Laboratory is the responsibility of an Administrative Staff and a Steering Committee. The Administrative Staff of the Laboratory is:

Robert J. Maurer, Professor of Physics, Director

John K. Stanley, Business Manager

The Steering Committee of the Laboratory is:

C. J. Altstetter, Professor of Physical Metallurgy: Acting Head, Department of Metallurgy and Mining Engineering

H. G. Drickamer, Professor of Chemical Engineering and of Physical Chemistry

A. L. Friedberg, Professor of Ceramic Engineering: Head, Department of Ceramic Engineering

Nick Holonyak, Jr., Professor of Electrical Engineering

R. O. Simmons, Professor of Physics; Head, Department of Physics

R. J. Maurer, Professor of Physics (ex-officio)

An External Advisory Committee advises the Director and Steering Committee concerning the quality of the research program, the wisdom of the choice of research directions, the functioning of the Central

Facilities, and the appropriateness of the organization and administration. The members of. the External Advisory Committee are:

J. Burke, General Electric Company

W. D. Compton, Ford Motor Company

M. Nevitt, Argonne National Laboratory

A. Overhauser, Purdue University

R. Oriani, U. S. Steel Corporation, Chairman

C. A. Swenson, Iowa State University 
The operation of the Laboratory is assisted by the committees and facilities listed below:

Health and Safety

F. Wise, C. Evans; J. Stanley

Machine and Faculty-Student Shop

F. Wise, H. Stapleton

Chemical Analytical Laboratory

C.' Evans, G. DePasquali

Toxic Materials Laboratory

S. Brown

High Temperature Laboratory

S. Brown

Magnet Facillty

F. Brown, C. P. Slichter

Materials Test Laboratory

C. Altstetter

Microstructure Laboratory (Electron Microscope, Electron Microprobe, Scanning Electron Microscope, X-Ray Laboratory, and Metallography Laboratory)

C. Wert, H. Fraser, J. Woodhouse

Crystal Growth Laboratory

H. B1rnbaum

Accelerator Laboratory ( 3 MEV Van de Graaf)

J. Koeh1er

Cryogenic Laboratory

D. Ginsberg 
Optical Laboratory (U1traviolet, Infrared, and Raman Spectrophotometers) M. Klein

Computer System (SIgma 5)

A. B. Kunz, H. J. Stapleton, V. Metze

Autotrol, Key Punches, Calculators, Typewriters

D. Ginsberg, J. Stanley

Reading. Room

R. Maurer

Seminar

R. Maurer 
The Professlonal Staff of the Laboratory 1s:

Chemical Analytical Laboratory

C. A. Evans, Ph.D., Senfor Research Chemist

R. J. Blattner, M.S., Research Chemist

J. Baker, B.A., Assistant Research Chemist

C. Silber, B.A., Assistant Research Chemlst

P. Williams, Ph.D., Research Chemlst

Microstructure Laboratory

J. Woodhouse, B.A., Research Microprobe Analyst

I. D. Ward, Research Metallurgist

Accelerator Laboratory

A. Delio, Accelerator Technician

B. Clymer, Accelerator Techniclan

Computer System (Sigma 5)

V. Metze, Research Programmer

(also, part-time student operators are employed)

Mr. F. Wise, B.A., is Technical Services Supervisor with responsibility for the Machine Shop and General Storeroom. 
Terminated Projects

None

New Projects

Jiri Jonas, Professor of Chemistry

Harry Drickamer, Professor of Chemlstry. and Chemlcal Engineering Dynamic Structure of Supercritical Dense Water and Aqueous Electrolyte Solutions

Supported by the Energy Research and Development Administration

Awards and Honors

Professor D, Lazarus, Department of Phystcs, Member, Executive Committee, APS Division of Solid State Physics, 1974-78.

Professors P. A. Beck, Department of Metallurgy, and C. P. Slichter, Department of Physics, Wakeffeld Recognition Award (University of Illinois) for excellence in education, research, and unfverstty service, 1975.

Leaves of Absence

H. K. BIrnbaum - II Semester 1974-75 (England) AERE Harwell

C. A. Wert - 1974-75 - Head, Metallurgy and Materials Section, Division of Materials Research, National Science Foundation

W. S. Williams - 1974-75 - Energy Coordinator, Division of Materials Research, National Science Foundation

\section{$\underline{\text { Trave1 }}$}

R. O. S1mmons, Professor of Physics

Presented an invited paper at the International Conference on Quantum Crystals, Tbilissi, USSR

Visited 1) Physico-Technical Institute of the Academy of the Ukrainian SSR, Kharkov, USSR; P. N. Lebedev Physical Inst1tute of the Academy of the USSR, Moscow; Service de Phys1que du Solide, Commissarlat a 1'Energle Atomique, CEN Saclay, France

No cost to the contract

H. L. Fraser, Assistant Professor of Metallurgy and Mining Engineerting

International Crystallography Conference on Diffraction Studies of Real Atoms and Real Crystals, Melbourne, August 9-23, 1974.

Eighth International Congress on Electron Microscopy, Canberra, August 25-31, 1974.

No cost to the contract 
Visiting Staff Members

Kazuhiro Otsuka, University of Tokyo, is a Visiting Research Assoclate Professor, Department of Metallurgy, June 1, 1974 through May 31, 1975, and is associated with Professor C. M. Wayman's project.

\section{Other Visitors of the Laboratory}

Dr. R. Smoluchowsk1, Princeton Unfversity, visited the Laboratory and gave a Physics-MRL Seminar, "The Structure of Jupiter $\mathrm{CH}_{2}$ and He Under Extreme Pressure)," March 29, 1974.

Dr.W. K. Chu, Department of Electrical Engineering, California Institute of Technology, Pasadena, visited the Laboratory and gave a seminar, "Surface and Thin Film Analysis by High Energy (2MeV) Ion Scattering Spectrometry," April 1, 1974.

Professor John Waugh, Department of Chemistry, Massachusetts Institute of Technology, Cambridge, visited the Laboratory and gave a Physical ChemistryMRL Seminar, "NMR of Dilute Spins; Applications to Chemistry and Blochemistry," April 17, 1974.

Dr. Plerre Longe, University of Llege, Belgium, visited the Laboratory and consulted with Professor J. Dow, Department of Phys1cs, Apr11 29, 1974.

Dr. R. F. Hehemann, Division of Metallurgy and Materlals Sclence, CaseWestern Reserve University, Cleveland, Ohio, visited the Laboratory and consulted with Professor C. M. Wayman, Department of Metallurgy, May 8 10, 1974 .

Dr. P. Krishna, Banaras Hindu University, Varanas1, Ind1a, visited MRL on May 23, 1974, to discuss recent research on silicon carblde.

Professor Masao Shimizu, Nagoya University, Japan, visited the Laboratory and consulted with Professor P. Beck, Department of Metallurgy, about invar problems, June 24-25, 1974.

Dr. K. Bönig, University of Münich, Germany, visited the Laboratory and had research discussions with the J. S. Koehler group, Department of Physics, June 28 - July 1, 1974.

Professor Milton Ferrelra de Souza, Universidade De Sao Paulo, Sao Carlos, Brazil, visited the Laboratory and consulted with :D1rector R. J. Maurer about Fourier Transform Spectroscopy, July 18-20, 1974.

Dr. Sudraud, Laboratorie des Solid State, Unfversity of Paris, Orsay, gave a seminar "Field Desorption of Organic Liquids," and consulted with Professor J. S: Koehler, Department of Physics, August 14-16, 1974. 
Professor T. Hehenkamp, University of Göttingen, Germany, visited the Laboratory and consulted with Professor D. Lazarus' group, Department of Physics, August 25, 1974.

Professor H. Wollenberger, University of Aachen, Germany, gave a PhysicsMRL Seminar, "Defect Production by Electron Damage In Gold," and consulted with Professor J. S. Koehler, Department of Physlcs, August 27, 1974.

Professor Etienne Guyon, Unlversite de Par1s, Orsay, France, visited the Laboratory and had discussions with Professor. W. L. McMillan, Department of Physics, September 3, 1974.

Dr. H. J. Lleb1, Max Planck Institut für Plasmaphysik, Garching bel Munchen, W. Germany, gave a seminar "Ion Microprobes and the Mattauch-Herzog Geometry" and consulted with Dr. C. A. Evans, September 19, 1974.

Dr. Ronald Linz, Solid State Science, Argonne National Laboratory, discussed effects of dislocations with Professor A. C. Anderson, Department of Physics, and gave a seminar, "Dislocation Lattice Resistivity in Concentrated Alloys," September 17,1974 .

Professor J. Weertman, Department of Materials Sclence, Northwestern University, Evanston, consulted with Professor Jon Holder, Department of Geology, about ice research evaluation, October 31, 1974.

Professor L. P. Gor'kov, L. D. Landau Institute of Theoretical Physics, Moscow, USSR, conducted a speclal seminar, "Toward a Theory of Superconductivity in the A-15 Compounds," and had discussions with the MRL theoretical group (J. Bardeen, Department of Physics), November 1-4, 1974.

Dr. Sonnenberg; Jillich, Germany, visited the Laboratory and gave a talk on "Recovery of Electron Irradiated $\mathrm{Pb}$ and $\mathrm{Cu}, "$ November 14, 1974.

Dr. Elliot R. Bernstein, Department of Chemistry, Princeton University, gave a seminar, "Interactions in Molecular Crystals: Spectroscopic Studies of Transition Metal Hexafluorides," and consulted with Professor $\mathrm{J}$. Dow on continuing collaboration on spin lattice relaxation research, November $21,1974$.

Dr. Peter de Chatel, Physical Sclence Laboratory, University of Amsterdam, visited the Laboratory and gave a talk on "Charge Transfer in Alloys," December 12, 1974.

Professor Humphrey J. Marls, Department of Physlcs, Brown University, visited the Laboratory and consulted with the Director of the Laboratory on liquid hellum research, February 20, 1975.

Dr. Hartmut Wiedersich, Argonne National Laboratory, visited the Laboratory and gave a joint Metallurgy-MRL Seminar, "High Temperature Radiation Damage," March 5, 1975. 


\section{S1gniflcant Results}

C. J. Altstetter

INTERSTITIAL SOLID SOLUTIONS

Hardening of Vanadium by Dispersed Hard Particles

The Ashby theory, heretofore applied only to fcc materlals, was shown to predict the work hardening behavior of this refractory metal having potential usefulness as a structural material in nuclear reactors. From this we are able to state that bcc alloys, such as ours, containing platelet particles are distinctly preferable to the more commonly studied systems using spheroldal particles. This indicates that the processing of such dispersion-strengthened materials w11l also have to be rather different. Our electron microscopy results suggest reasons for the limited ductility of high interstitial solute bcc metals. They demonstrate how the by-pass of particles by dislocations is fundamentally different from fcc alloys and consequently how the basic deformation rate limiting process differs in bcc and fcc metals.

P. A. Beck

ELECTRONIC STRUCTURE AND MAGNETISM OF TRANSITION METAL ALLOYS

During the last four years an appreciable part of our research effort was directed at the exploration of mictomagnet1sm, a type of magnetic behavior distinctly different from both ferromagnetism and antiferromagnetism. Other research groups also became interested in this new area. As a result of all these efforts, it is now quite clear that an unexpectedly large number of solid solution alloys with at least one magnetic component have mlctomagnetic character. This new class of magnetic materials has several characteristic features, which may be of technological importance; at the time of writing it is difficult to assess the range of their posstble use. At any rate, the unique features of mictomagnetic alloys ("spin glasses") have already aroused considerable theoretical interest ( $P$. W. Anderson, Mat. Res. Bul1. 5, 549 (1970). Localisation Theory and the Cu-Mn' Problem: Spin Glasses).

H. K. Birnbaum

POINT DEFECT - DISLOCATION INTERACTIONS

The role of trapping sites in determining the diffustonal behavior of hydrogen and its isotopes has been determined in the bcc metals $\mathrm{Nb}$ and $\mathrm{Fe}$. In both cases the interactions between $H$ (and $D$ ) and other interstitial solutes have been determined and shown to have a strong effect on the low temperature diffusion processes. The relationships between the local motion of $H$ (D) in the trapped sites and the long range migration have been established. Very iarge departures from classical thermally activated diffusion processes have been established 
for $\mathrm{H}$ (D) in both $\mathrm{Nb}$ and $\mathrm{Fe}$. Large 1sotope effects, mobllity at temperatures of the order of $0.07^{\circ} \mathrm{K}$, non-Arrhenius behavior, isotopic dependence of the binding energies to traps have all been shown to be consequences of this non-classical behavior. Raman active modes of $\mathrm{H}$ have been established in $\mathrm{Nb}$ (in conjunction with Professor $\mathrm{M}$. Klein) and the local vibrational behavior has been studied. The studies of hydride precipitation (in conjunction with Professor H. Fraser) have revealed a new vacancy ordering phenomenon in off-stochiometric $\mathrm{NbH}$ and the resultant development of a new series of hydride structures.

The above results are of slgnificance to the fundamental understanding of diffusion mechanisms for light interstitials in bcc metals. In these cases non-classical tunnelling mechanisms have been shown to be of great importance. The measurements also have a close relationship to problems of the fast breeder and fusion reactor programs as they are related to the problems of hydrogen embrittlement, containment of radioactive tritium, void formation and a number of other englneering problems. The behavior of materials in hydrogen environments is also of interest in energy transport by gas pipelines and in the general area of stresscorrosion failure which is intimately related to the problems of hydrogen entry into the lattice and hydrogen embrittlement.

H. G. Drickamer

USE OF VERY HIGH PRESSURE TO INVESTIGATE THE STRUCTURE OF MATTER

The most significant achievement in our group in the past year is the development and inftial exploitation of techniques for luminescence measurements to 150 kilobars. We have done a rather thorough experimental study of aromatic hydrocarbons and purine and pyrimide bases and nucleosides in various environments. From our inftial studies on $\mathrm{ZnS}$ phosphors with various dopings it appears that a better classification of impurity effects will arise. Our studies on oxygenated phosphors provide a much more rigorous test than hitherto possible of the classifications of Blasse of Philips (Holland). (The above phosphors are important in TV and oscilloscope screens, in 1fghting, etc.) our studies on doped alkali halides have uncovered pressure induced transitions among excited states and a new test of resonant energy transfer. Initial studies on rare earth doped tungstates yield new information on energy transfer. (These are important laser materials.) When these measurements can be supplemented by thermoluminescence and lifetime studies at high pressure, they can lead to practical improvements in a variety of optical devices and more efficient use of electrical energy.

H. L. Fraser

DEFORMATION OF INTERMETALLIC COMPOUNDS AT ELEVATED TEMPERATURES

Work on the elevated temperature deformation of N1A1 has ylelded two important results. Firstly, we have shown that. the dislocations giving rise to plasticlty in $\langle 100\rangle$ crystals at elevated temperatures have 
Burgers vectors $b=\langle 100\rangle$. This is contradictory to previous work reported in the literature, where dislocations having $\underline{b}=\langle 110\rangle$ were thought to be responsible for plastic deformation. The present work has established that these dislocations are formed by the collision of appropriate dislocations of $\underline{b}=\langle 100\rangle$. Secondly, crystallographic analyses of dislocations in deformed specimens have shown that many do not have rational slip planes; this surprising result indicates that climb is a predominant mechanism of plastic deformation. in these crystals. These two results lead to an increased understanding of the deformation of $\mathrm{NIAl}$, and may result in an understanding of the plasticity of the polycrystalline compound at elevated temperatures.

In the hydride studies, a significant result is the observation that the hydride of $\mathrm{Nb}$ precipitated in thin foil has an ordered structure. The structure has been determined by means of electron microscopy. This result has increased our fundamental understanding of the hydride precipitation process.

Finally, during the assessment of the capabllities of scanning transmission electron microscopy (STEM), It has been found that when using STEM there is no increase in usable foll thickness for heavy element materials such as is observed in the case of light element materlals. This is due to the inelastic scattering processes that are predominant in these type of materials.

A. V. Granato

ANHARMONIC EFFECTS IN SOLIDS

Dislocations in lead have been found to be underdamped In both the normal and superconducting state at $4.2 \mathrm{~K}$. This is evidence in favor of the Granato inertial model and against the Natsch thermal actlvation model for the mechanical strength change of superconductors or changing state.

The two-thirds power dependence of the stress amplitude on temperature for constant decrement predicted by Granato and Lücke was observed in copper and aluminum crystals at low temperatures. This demonstrates that the force-distance profile for a dislocation and a single point defect can be determined experimentally. The results provide a basis for an understanding of the temperature dependence of the yleld stress of crystalline sollds.

J. S. Koehler RADIATION DAMAGE IN SOLIDS

During the past year we have: (I) Shown that Stage I annealing of lead is analagous to Stage $I$ in copper except that the annealing occurs at much lower temperature $\left(\mathrm{T}_{1 \mathrm{D}}(\mathrm{Pb})=4.1 \mathrm{~K}, \mathrm{~T}_{1 \mathrm{D}}(\mathrm{Cu})=37 \mathrm{~K}\right)$. Gold remains anomalous.

(2) Given a theory of steady state vold growth in irradiated pure metals and in alloys. This paper has been accepted for publication in the Journal of Applied Physics. 
D. Lazarus

DEFECT AND ELECTRONIC PROPERTIES OF SOLIDS

Studies of the effect of co-diffusion of trace impurities in alkall halide crystals have been completed, and the theoretical model has been improved to cover cases of higher Impurity concentration. These indicate that much of the published diffusion data of earlier workers may be considerably in error due to inadvertent contamination. Work has begun on an investigation of "superionic" conductors, which show great potential as solid electrolytes for battery and fuel cell use. Apparatus is nearing completion for studying electrical noise in these and other materials near phase transitions.

M. Metzger

DEFORMATION OF REINFORCED METALS

We have shown in a model fiber composite material that the initial matrix dislocation structure can be dominated by differential contraction strains and can strongly influence mechanical behavior at small strains. This is pertinent to fundamental understanding of technologlcal composite materials and to their design in regard to the relative importance of matrix initial structure versus matrix interaction with the nondeforming phase during deformation.

Film growth on aluminum in an aqueous electrolyte under nonpitting conditions was shown to be accompanied by transient pitting on a very fine scale. This pointed to the need for reformulation of conventional ideas concerning pitting corrosion in the presence of chlorides--the condition for pitting in the general sense is not that the passive film breaks down but that pit embryo growth occurs instead of repair. Knowledge of the microscopic processes occurring will guide further efforts at understanding and control of pitting corrosion. This work was also supported by ARO-D.

E. N. Pugh

THE MECHANISM OF STRESS-CORROSION CRACKING: PROPAGATION STUDIES

The stress-corrosion cracking (SCC) of structural materials continues to be a serious and costly practical problem in virtually all engineering applications. For example, recent faflures of condenser tubes in the Palisades Nuclear Power Plant have led to the continued shutdown of the plant and to lawsuits amounting to $\$ 300,000,000$. The most important result of our AEC supported research in this area has been the recognition that in a number of important systems the basic cause is hydrogen entry into the material. While further work is necessary to establish the specific role of hydrogen, this recognition indicates that we should begin to design alloys in terms of the relevant hydrogen-related processes, e.g. the surface reactions involved in hydrogen entry, and its diffusion in the lattice. 
T. J. Rowland

NUCLEAR MAGNETIC RESONANCE STUDIES

Data which will enable us to correlate time dependent macroscopic properties of three dimensional amorphous polymer networks (crosslinked elastomers) with lattice vibrational spectra is being obtained. This is of fundamental use in understanding and designing such networks.

C. P. S1ichter

NUCLEAR MAGNETIC RESONANCE IN SOLIDS

\section{A. Mágnetic Atoms in Non-Magnetic Metals}

Fe atoms, when dissolved in $\mathrm{Cu}$ in low concentrations, undergo a transition from being a strongly magnetic atoms at high temperatures to being a weakly magnetic atoms at low temperatures. This remarkable phenomenon is called the Kondo effect, and the temperature which roughly divides the $\mathrm{high}$ and low temperature regimes (29K for CuFe) is called the Kondo temperature. The theory of the Kondo effect has proved to be an exceedingly difficult many body problem but it is one of great importance since closely related problems are found in many. other parts of physics, such as in the theory of optfcal and $x$-ray absorption edges in solids.

For $\mathrm{CuFe}$ the effect is believed to result from the coupling of the spin of the magnetic atom to the spins of the conduction electrons. As a result, there is a magnetization cloud induced in the conduction electrons in the nefghborhood of the magnetic atom both above and below the kondo temperature.

It has been conjectured both on theoretical grounds and on the basis of some experiments that when one cools below the Kondo temperature, the spatial shape of the magnetization cloud changes, and that this shape change gives basic insight into the true character of the Kondo effect.

We have succeeded in using nuclear magnetic resonance to measure the spatial form of the magnetization in the vicinity of the magnetic atom for dilute alloy systems CuM where $\mathrm{M}$ is $\mathrm{Sc}, \mathrm{T} 1, \mathrm{~V}, \mathrm{Cr}, \mathrm{Mn}, \mathrm{Fe}, \mathrm{Co}$, and $\mathrm{Ni}$, the entire iron group. The method is based on the fact that the nuclei experience a magnetic field, in addition to the applied laboratory field, which is proportional to the conduction electron magnetization at the nuclear position through known constants of proportionality. Thus the resonance frequency of the nuclei near to the magnetic atom is displaced from the position for pure $\mathrm{Cu}$, the slze of the displacement giving the magnetization at that nuclear site.

We have followed the shape versus temperature for the magnetization cloud in $\mathrm{CuFe}$ from above to below the kondo temperature, proving that there is no shape change in the magnetization cloud resulting from the Kondo transition. 
Magnetic measurements on dilute alloys by conventional means such as use of a balance to measure susceptibility often have difficulties because one is not sure about what fraction of the magnetic atoms are dissolved in the host and what fraction precipltated in the form of small inclusions of the pure magnetic metal. By magnetic resonance of the magnetic atom one can distinguish dissolved atoms from the undissolved. We have applied this techntque to $\mathrm{V}$ and $\mathrm{Sc}$ in $\mathrm{Cu}$.

For $\mathrm{CuV}$ we showed that even with rather dilute alloys quenched from the melt there are substantial amounts of $V$ which form as clusters of pure $V$ rather than as isolated atoms in a $\mathrm{Cu}$ matrix. An interesting metallurgical application of our methods would be the systematic study of the phase diagrams of these dilute alloys. For CuSc we find dissolved Sc, Sc in a compound (probably CuSc), but no Sc metal.

The results on $\mathrm{CuSc}$, CuTi, and $\mathrm{CuV}$ are some of the very first magnetic measurements on these metallurgically difficult materials. (We find that the $\mathrm{V}$ atom has magnetic properties very similar to $\mathrm{Co}$, but has much larger electric field gradients.)

By studying the nuclear magnetic resonance of single crystals. of $\mathrm{Cu}$ containing $\mathrm{Mn}, \mathrm{Fe}$, $\mathrm{Co}$, and $\mathrm{NI}$ as a function of the orientation of the magnetic field with respect to the crystal axes, we have been able to assign some of the many resonance lines we see to particular shells of neighbors (e.g. 1st nelghbor, 2nd neighbor) for those systems. We hope thereby to deduce the energy levels and energy level widths of the $\mathrm{d}$-electrons of these atoms in $\mathrm{Cu}$. These quantities are central to P. W. Anderson's theory of such alloys, but have never been measured before.

We have observed that the magnetic atom couples to nuclel of nearby atoms not only with the usual magnetic dipole coupling and the usual isotropic hyperfine coupling but also.with a so-called pseudodipole coupling which is about three times larger than the magnetic dipole coupling. This is the first observation of a pseudodipolar coupling in a metal. The large size and the strong anisotropy of the pseudodipole coupling has not been previously predicted. We have developed a tentative explanation which we hope will prove correct. If it does, it will provide evidence for energy level splittings of the magnetic ion additional to those ordinarily belleved to exist. This will further buttress the theoretical picture of the magnetic alloys.

Overhauser proposed that charge density waves might occur in the alkali metals, being responsible for certain anomalous properties reported by experimenters. It now seems to be generally agreed that one has spectal requirements on the shape of the Fermi surface for the charge density waves to exist, requirements not met by the alkall metals, but satisfied by substances such as $\mathrm{TaS}_{2}$ (see below) in which recently charge density waves have been seen. For his stimulus in predicting this phenomenon, Overhauser is being awarded the Buckley Prize of the American Physical Society this year. 
Several years ago, we decided to use nuclear magnet1c resonance to test whether or not. charge density waves existed in $\mathrm{K}$ metal. Our analysis showed that charge density waves could show up (1) In the KnIght shift (2) In static quadrupole coupling (3) in spin lattice relaxation. We have completed these experiments and find that it is highly unlikely that there is a charge density wave (either static or a time-varying one) of the magnitude assumed by Overhauser for $K$. We are in the process of writing up the work for publication. We plan to carry out studies of charge density waves in transition metal dichalcogonides, systems where they are now known to occur as described below. It is interesting to note that their discovery (in $\mathrm{NbSe}_{2}$ by Gossard and Ehrenfreund) was made by nuclear magnetic resonance, the method we were using for potassium.

C. M. Wayman

SOLID STATE PHASE TRANSFORMATIONS AND THIN FILMS

Progress has been made in three areas which may eventually lead to technological advantage. (1) Experiments on shape memory alloys have been carried out with a view to studying the engine like behavior of these alloys. It is known that such alloys can be deformed with comparative ease while in the martensitic state; however when they (as deformed) are transformed back to the parent phase condition by heating, the original shape (undeformed condition) is recovered. This recovery results in the generation of substantial stresses. An analysis of the energetics of this process shows that an efflciency of $20 \%$ may be reallzed for the direct conversion of heat into mechanical energy. Although the work is in a crude stage at present, it is indicated that "energy converters" or "solid state engines" based on the shape memory effect may be important for the conversion of solar energy or waste heat into mechanical energy.

(2) Continuing work on martensitic alloys has shown that certain pretransformation lattice instabilities are observed by electron microscopy and diffraction. Diffuse electron diffraction scattering and image "shimmering" of a crystallographic nature indicate that events of a premonitory nature may precede the actual transformation itself. Since all previously proposed nucleation models for martensitic transformations have been lacking in one respect or another, it is indicated that a new mode for the nucleation of such transformations may be forthcoming. Since the martensitic type of transformation is technologically important for a number of reasons (the hardening of steel, maraging, "TRIP" phenomena, and the shape memory effect), it follows that new. Insights into the premonitory behavior may lead, eventually, to controlled nucleation processes.

(3) Further studies, using princlpally electron microscopy and diffraction, have indicated that the formation of hydrides in certain metals involves a process very simflar to the coordinated atom transfer characteristic of martensitic transformations. Our efforts have focused on the nature of the hydride-parent phase interface, and more speclfically on the dislocation arrays in such interfaces which lead to a highly mobile boundary between phases. Since metallic hydrides usually contain a large concentration of 
hydrogen, and thus may be suitable as energy storage devices, it is felt that the present work in this area will lead to an eventual understanding of both the formation and dissolution (reverse transformation) of these phases.

C. A. Wert

PRECIPITATION IN REFRACTORY METAL ALLOYS

Two pieces of work have been completed. Both involve the refractory metals tantalum and vanadium. The first is the study of solid solubility of hydrogen and deuterium in tantalum and vanadium and formation of hydrides and deuterides in these metals. Many earlier studies of the phase relations in the Ta-H, Ta-D, $\mathrm{V}-\mathrm{H}$ and $\mathrm{V}-\mathrm{D}$ blnary alloys have been reported; the data are extremely conflicting. We determined that the chief difficulty was the slowness of achlevement of equilibrium at low temperatures (say $100^{\circ} \mathrm{K}$ ), in particular if a little oxygen is present. As solid solutions are cooled toward temperatures at which the hydride first forms, cooling rates no larger than a few degrees $\mathrm{K}$ a day must be used to ensure equilibrium. By use of slow cooling rates, we have determined the enthalpy changes which occur when the hydrides and deuterides form in both metals. We find no difference in these enthalpy changes in $\mathrm{Ta}$ between $\mathrm{H}$ and deuterium, both are $2150 \mathrm{cal} / \mathrm{mole}$. Neither are there differences between $H$ and $D$ in vanadium, both enthalpies are $3900 \mathrm{cal} / \mathrm{mole}$. Our work in vanadium is slightly different from that of Westlake and Ockers at Argonne. By exchange of.speclmens, we hope to eliminate these small, but significant differences.

The hydrides are about 10\% less dense than the metals, therefore formation of hydrides is accompanied by large lattice strain. The strain is largely taken up by ejection of dislocation loops into the metal around the hydrides. By electron microscopy we have determined these loops in tantalum to be interstitial (1.e. excess atom planes), of edge type and with Burgers vector [111].

From a metallurgist's point of view, these are basic studies of the thermodynamic parameters of solid solutions, hydrides and deuterides in refractory metals. They are the first detalled observations of properties of dislocations ejected by hydrides in these metals. From a practical view, they are important because of the high probability that these metals will be used in containment vessels for thermonuclear reactors in the presence of $H, D$ and $T$.

The second study, which is less complete than the flrst, is a study of carbide formation in the ternary system $\mathrm{V}-\mathrm{Ti}-\mathrm{C}$. We had already determined the rates of formation of vanadium carbides in vanadium at temperatures between $200^{\circ} \mathrm{C}$ and $600^{\circ} \mathrm{C}$. We had already determined the nature of the thin carbide plates and their geometry in the host metal V. We found that considerable hardening accompanled the formation of the carbide, but that the alloy quickly softens above $500^{\circ} \mathrm{C}$. The addition of a strong carbide former, $\mathrm{Ti}$, pushes the temperature up to more than $1000^{\circ} \mathrm{C}$. We have made initial studies of 
the small V TI C plates using electron microscopy, but we do not yet know the composition of the carbides, the thermodynamic and kinetic features of their formation, nor how stable they can be made. Thls study has much practical significance; just as one does not often use binary $\mathrm{Fe}-\mathrm{C}$ steels; but instead uses steels with alloying elements to form more stable carbides, so do we need to understand the basfcs of carbide formation in $\mathrm{V}, \mathrm{Ta}$ and $\mathrm{Nb}$.

W. S. Williams

PHYSICS OF REFRACTORY MATERIALS

We have identified from first principles the origin of the strong bonding in the refractory compound TiC. Using the method of local orbitals, we have calculated the electron density in real space for three materials having the same (rocksalt) structure but different degrees of Ionicity/ covalency: $\mathrm{NaCl}, \mathrm{MgO}$ and $\mathrm{TIC}$. In this series, the location of the charge density minimum moves from near the metal for $\mathrm{NaCl}$ to approximately the midpoint between metal and non-metal species for T1C. Furthermore, the overlap between orbitals centered on the metal and non-metal increases as $0.08,0.14$ and 0.33 , respectively, with 0.50 representing the maximum possible. Thus the strong bonding in the carbide results from the formation of a covalent bond with some polar character between metal and non-metal atoms. This theoretical treatment of the bonding controversy in the transition-metal carbides is perhaps the most fundamental and Illuminating of several approaches reported, and with further development will help us rationalize in detail the observed extreme properties of great hardness, high melting point and large elastic constants of this class of semi-metallic ceramics. With such detailed understanding available, systematic property modification might be obtained through enlightened selection of substitutional impurities to influence the electronic structure.

R. O. Simmons

PROPERTIES OF NOBLE GAS CRYSTALS

1) Phase transitions in crystalline methane have been studied by diverse experimental and theoretical means. This project has now studied the methane crystal structure and lattice expansion, especially near the upper phase transition in $\mathrm{CH}_{4}$, which has proved to be first order. Previous data in the literature showed, to the contrary, an apparent higher order behavior, which we now know to be the result of nonequilibrium experimental conditions. Modern theories of phase transitions can be tested with this "model" molecular solid. 2) In real insulating solids, anharmonicity of the lattice accounts for thermal expansion and thermal conduction. Understanding such anharmonicity is therefore important, and a highly anharmonic "model" crystal for this purpose is solid argon, which can be studied over a wide range of conditions. Raman spectra of argon and argon-krypton mixtures, compressed up to $4 \mathrm{kbar}$, have yielded independent information about lattice vibration spectra and anharmonicities. 
PROJECT TITLES AND PRINCIPAL INVESTIGATORS

NT-03-01-01-0 Structure of Materials

Electronic Structure and Magnet1sm of Transition Metal Alloys

Paul A. Beck, M.S., M.E., Professor of Physical Metallurgy

Dynamic Structure of Supercritical Dense Water and Aqueous Electrolyte Solutions

Harry G. Drlckamer, Ph.D., Professor of Chemical Englneering and of Physical Chemistry.

Jiri Jonas, Ph.D., Professor of Chemistry

Solid State Phase Transformations and Thin Films

C. Marvin Wayman, Ph.D., Professor of Metallurgical Engineering

NT-03-01-02-0 Mechanical Properties

Point Defect - Dislocation Interactions

Howard K. Birnbaum, Ph.D., Professor of Physlcal Metallurgy

Deformation of Intermetallic Compounds at Elevated Temperatures

Hamish L. Fraser, Ph.D., Assistant Professor of Metallurgy

Deformation of Reinforced Metals

Marvin Metzger, Ph.D., Professor of Physical Metallurgy

The Mechanism of Stress-Corrosion Cracking: Propagation Studies

E. Neville Pugh, Ph.D., Professor of Metallurgical Engineering

Precipitation in Refractory Metal Alloys

Charles A. Wert, Ph.D., Professor of Physical Metallurgy; Head, Department of Metallurgy and Mining Engineering

NT-03-01-03-0 Phystcal Properties

Interstitial Solfd Solutions

Carl J. Altstetter, Sc.D., Professor of Physical Metallurgy;

Acting. Head, Department of Metallurgy

Nuclear Magnetic Resonance Studies

Theodore J. Rowland, Ph.D., Professor of Physlcal Metallurgy 
NT-03-02-02-0 Experimental Research

Use of Very High Pressure to Investigate the Structure of Matter Harry G. Drfckamer, Ph.D., Professor of Chemfcal Engineering and of Physical Chemistry; Member, Center for Advanced Study

Anharmonic Effects in Solids

Andrew V. Granato, Ph.D., Professor of Physles

Defect and Flectronfc Propertles of Solids

David Lazarus, Ph.D., Professor of Physles

Properties of Noble Gas Crystals

R. O. Simmons, Ph.D., Professor of Physics; Head, Department of Physics

Nuclear Magnetic Resonance in Solids

Charles P. Slichter, Ph.D., Professor of Physics; Member, Center for Advanced Study

Physics of Refractory Materials

Wendell S. Williams, Ph.D., Professor of Physics, of Ceramic

Engineering, and of Bloenglneering

\section{NT-03-02-04-0 Particle Solid Interactions}

Radiation Damage in Solids

James S. Koehler, Ph.D., Professor of Physics 
METALLURGY AND CERAMICS

NT-03-01-01-0 Structure of Materials

Electronic Structure and Magnetism of Transftion Metal Alloys

Principal Investigator: Paul A. Beck, M.S., M.E.

Professor of Physical Metallurgy

Supporting Agency: U. S. Atomic Energy Commisston

Sentor Staff: Paul A. Beck, Professor

Junior Staff: Robert D. Shu1l, Research Asststant

Randal W. Tustison, Research Assistant

Object: Magnetic alloys are technologlcally Important In varlous applications, such as electric motors, generators, transformers, and computer memory devices. The present project aims to contribute to a better fundamental understanding of magnetism in alloys of the $3 d$ transition metals by studying (1) the effect of local atomfc environment on the moment associated with $3 \mathrm{~d}$ metal atoms and (2) the magnet1c properties and the magnetic structure of mictomagnetic ("spin glass") alloys, which were shown in recent years to be much more prominent among atomically disordered solid solutions than previously suspected.

Results, FY75: (a) The experimental study of the magnet1c properties of $\mathrm{Au}-\mathrm{V}$ alloys from $0.5 \% \mathrm{~V}$ to $20 \% \mathrm{~V}$ in the temperature range from $1.5^{\circ}$ to about $450^{\circ} \mathrm{K}$ has been completed. Ordered $\mathrm{Au}_{4} \mathrm{~V}$ was found to be ferromagnetic, as described in the literature. "The large difference in the magnetization at low temperatures between the fleld cooled and the zero-field cooled state apparently arises not from mictomagnetism, but: from an extraordinarily large hysteresis, which is probably due to the unusually large number of the types of atomic order domains, with a correspondingly high concentration of order domain boundaries.

(b) Low alternating field susceptibility measurements on $\mathrm{Fe}_{3} \mathrm{~A} 1$ with $\mathrm{Al}$ contents higher than stolchiometric show a sharp susceptibility peak at temperatures depending on the Al content. These alloys are ferromagnetfc at around room temperature up to about $30 \% \mathrm{Al}$. The suscept1bility peak at low temperatures indicates the presence of mfctomagnetism in the $30,30.5,31$, and $32 \% \mathrm{~A} 1$ alloys. The changeover from ferromagnetism to mictomagnetism with decreasing temperature in some of these alloys is a very unusual phenomenon and it is being studied intensively.

(c) A detalled study has been started of the temperature- and flelddependence of the rate of Increase in magnetization with time in zerofield cooled $\mathrm{Cu}-\mathrm{Mn}$ alloys, following the application of a magnetic fleld. Preliminary results suggest that the prevfously proposed equation, describing the "quasi-viscous" behavior of such mictomagnetic alloys, is probably applicable. 
(d) A new instrument has been constructed for the measurement of remanence as a function of temperature and of time in mictomagnetic alloys. This instrument is currently being tested and we hope to put it in use in the near future.

Results Expected, FY76: We expect to continue the study of magnet1c relaxation phenomena in $\mathrm{Cu}-\mathrm{Mn}$ and in other mictomagnet1c alloys." These studies will be made by using a new, improved version of the alternating low field susceptibility apparatus, the newly bullt remanence meter now being tested, and steady field magnetization measurements with zero-field cooled specimens. As a result of such measurements, it is expected to obtain data on the relaxation time as a function of temperature, fleld, and metallurgical treatments affecting the average moment and the concentration of magnetic clusters. Using the new remanence meter, we also expect to obtaln detafled information on the nature of the novel transition on cooling from the ferromagnetic to the mictomagnetic state in $\mathrm{Fe}-\mathrm{Al}$ alloys near $\mathrm{Fe}_{3} \mathrm{Al}$.

Results Expected, FY77: The proposed equation, describing the "quas1viscous". magnetic behavior of mictomagnetic alloys in terms of a barrier energy, will be fully tested. If it is found to be a valid description of the experimental data, the barrier energy will be determined as a function of metallurgical treatments, which alter the short range atomic order in the alloys. These studies should result in a much better understanding of the effect of metallurgical treatments on magnetic properties than heretofore available.

Other Work: The Fe-Al alloy specimen prepared for Dr. F. Mezel at the von Laue-Langevin Institute in Grenoble, France; has ytelded some very. interesting results from neutron depolarization vs. temperature measurements. A single crystal cut out from this specimen was also used at the same Institute for Mössbauer measurements with very interesting results. In both directions, the work is still continuing.

We received magnetization data from Dr. Tholence, Grenoble, France, on $\mathrm{Au}-\mathrm{Fe}$ alloys measured at very low temperatures, down to $0.06^{\circ} \mathrm{K}$, and up to fields of $67 \mathrm{kOe}$. Although under the conditions described the scatter of the experimental data is much larger than under more conventional conditions of temperature and fleld, we succeeded in obtaining a reasonable fit to these data with a susceptibility term and a Brfllouln function, using our new least squares fitting program.

We also recelved low temperature magnetization vs. fleld data for CoGa from Professor F. Gautier, Strasbourg, France, and we were able to fit these data well with two Brillouln functions.

We supplied a carefully prepared specimen of $\mathrm{Cu}_{75} \mathrm{Mn}_{25}$ to Dr. J. J. M. Franse, The Unfvers1ty of Amsterdam, Holland, who will make magnetovolume and thermal expansion measurements on 1t. The results should be of great interest in connection with our studies of the magnet1c structure of this alloy. 
We supplied a specimen for ESR measurements to Professor R. Orbach of UCLA, Los Angeles, California, who is interested in studying the "ESR transition temperature" as a function of the frequency of the alternating field used for the measurements. The results may help in evaluating our recent proposal for the interpretation of the ESR transition temperature.

Publications, Calendar Year 1974:

D. J. Chakrabart1

Effect of Atomic Ordering on the Magnetic Properties of $\mathrm{Pd}_{3} \mathrm{Mn}$ and of Some More Dilute Pd-Mn Alloys

International Journal of Magnetism 6, 305-311 (1974). COO-1198-1041

B. de Mayo

Magnetism in Gold-Iron Alloys Below 14 at.\% $\mathrm{Fe}$

Journal of the Physics and Chemistry of Solids 35, 1525 (1974)

COO-1198-854

S. Mishra, E. J. Hayes, R. Tustison, and P. A. Beck

Magnetism in $\mathrm{Ni}-\mathrm{Cu}$ and $\mathrm{Co}-\mathrm{Re}$.Solid Solutions

Journal de Physique 35, C4-194 (1974)

CO0-1198-1026

A. Mukhopadhyay, R. D. Shu1l and P. A. Beck

Relaxation and Magnetic Clusters in Mictomagnetic Cu-Mn Alloys

Physical Review B (submitted to)

COO-1198-1136

R. D. Shull and Paul A. Beck

Mictomagnetic to Ferromagnetic Transition In $\mathrm{Cr}-\mathrm{Fe}$ Alloys

Proceedings of the 20th Conference on Magnetism and Magnet 1c Materials,

San Francisco, 1974 (submitted to)

C00-1198-1116

M.S. Theses, Calendar Year 1974:

None

Ph.D. Theses, Calendar Year 1974:

None 
Dynamic Structure of Supercritical Dense Water and Aqueous Electrolyte Solutions

Princlpal Investigators: Harry G. Drickamer, Ph.D. Professor of Chemlcal Englneerling and of Physical Chemistry

Jirl Jonas, Ph.D.

Professor of Chemfstry

Supporting Agency: U. S. Atomic Energy Commtssion

Senior Staff: Harry G. Drickamer, Professor

Jiri Jonas, Professor

John W. Linowski, Research Associate

Junior Staff: Michael Fury, Research Assistant

T. DeFries, Graduate Student (ARPA)

Object: The overall goal of the proposed research ls the exploration of the dynamic and static structure of matter at high temperature and pressure. Nuclear magnetic resonance measurements w1ll be made on the dynamfc structure of liquids to temperatures of $1300^{\circ} \mathrm{K}$ and to pressures of 5 to $10 \mathrm{kbars}$. Thermoluminescence data will be obtained on a variety of materials, ultimately to $1000^{\circ} \mathrm{K}$ and $100 \mathrm{kilobars,}$ to clarfiy the electronic structure of glasses, polymers, and laser matertals.

The main emphasis will be on NMR studies of transport properties of electrolytes in superheated compressed steam because of the existence of a proposed process for separation of uranium lsotopes using this spectfic medium. This process is under constderation by the Oak Ridge National Laboratory. The efficiency of the isotope separation is considerably enhanced when superheated compressed steam is used as a solvent medium.

Results, FY75: Initial stages of this new project have been finished. The high temperature; high pressure NMR equipment was designed and we expect to be in operation within several months. A related study of the effects of density on hydrogen bonding in liquid ethanol was finished in order to test the NMR equipment for accuracy in chemfcal shift measurements by Fourfer transform technique. A thermoluminescence apparatus has been constructed and is being tested. In 1 ts present form it should operate from $77^{\circ} \mathrm{K} \rightarrow 500^{\circ} \mathrm{K}$ and to $130 \mathrm{k} 1$ lobars.

Results Expected, FY76: Transport properties of varlous electrolytes dissolved in high-pressure supercritical steam w111 be measured. Additional optical experiments will be also carried out in order to elucidate detalled mechanism of transport of salts ln the high pressure supercritical steam. We expect to obtain, first, high pressure thermoluminescence data, testing a few inorganic and polymer systems. Initial 
work on the design and testing of the NMR equipment for the studies of solids to $100 \mathrm{~kb}$ ars $1 \mathrm{~s}$ planned.

Results Expected, FY77: The dynamic structure measurements w111 be extended to include fused salts and liquid metals. Small scale model of equipment for separation of isotopes using high-pressure supercritical steam as a solvent will be built and tested. Th1s 1sotope separation process will be evaluated. If successful, this process may have major technological importance for the AEC. Thermoluminescence data on rare earth ions in laser materlals and on polymers should be obtalned. . NMR studies of varlous solids and polymers at very high pressures up to $100 \mathrm{~kb}$ ars will be carried out.

Other Work: We are in correspondence with the Isotope Development Center at the Oak Ridge National Laboratory who is considering the feasibility of using high pressure supercritical steam as a solvent for Ionizable inorganic salts. This spectal solution is then used in an electrolytic counter-current flow to enrich 1sotopes. We plan to provide the Oak Ridge Laboratory with our results on transport properties of various electrolytes in the high-pressure supercritical steam and also assist with our expertise in high pressure techniques if evaluation of the process on a practical scale is declded upon. We expect to develop a close working relationship between the Isotope Developmental Center and our research group. Close contact is maintalned with NMR and high pressure research in other laboratories. No duplication of effort will exist.

Publications, Calendar Year 1974:

None

M.S. Theses, Calendar Year 19.74:

None

Ph.D. Theses, Calendar Year 1974:

None 
Solid State Phase Transformations and Thin F1lms

Principal Investigator: C. Marvin Wayman, Ph.D. Professor of Metallurglcal Englneering

Supporting Agency: U. S. Atomic Energy Commisston

Senior Staff: C. Marvin Wayman, Professor

Kazuhiro Otsuka, Visiting Research Assoclate Professor

Junior Staff: Mfchael P. Cassidy, Research Asslstant

S. Chakravorty, Research Assistant

Jun Ich1 Fujita, Research Assistant

Myung-Hwan Kim, Research Assistant

Object: Solid state phase transformations of the martensitic type are belng studied with emphasis on pretransformation lattice instabilities and phase nucleation, materials properties and mechanisms of the shape memory effect, and the crystallography of hydride formation in metals. The first program deals with understanding and hopefully controlling phase nucleation. The second involves a study of material properties as related to the feasibility of the shape memory effect in the direct conversion of heat into mechanical work. The third attempts to define the mechanism of hydride formation, a phenomenon of current interest for posstble energy storage devices. Both bulk materials and thin films prepared by sputtering, evaporation, and thinning are examined through phystcal properties measurements and electron microscopy and diffraction analysis.

Results, FY75: Further research has led to a more detalled understanding of "memory" alloys and the shape memory effect, with particular emphasis on thermodynamics. Temperature regimes for thermoelastic behavior and the effects of applied stress have been documented. An efficiency analysis of "solid state engines" based on the shape memory effect has been carried out, and the first approximation Indicates that effictencies as high as $20 \%$ may be possible for the direct conversion of heat into mechanical work via the shape memory effect. This effect may be of future technological significance.

Both electron diffraction and transmisston electron microscopy have been used to study pretransformation "anticlpation" phenomena in a number of materials which undergo martensitic transformations at lower temperatures. Oualitative observations of the intensification of lattice oscillations as the transformation temperature is approached have been made both by transmission imaging and broadening effects in electron diffraction. Crystallogrephic features of the lattice instab 11 ltfes have been related to the geometry of the Bain strain of martens1t1c transformations, and may eventually be related to the (non-classical) mode of nucleation in martensites. 
It has been established that hydrides in vanadium possess many of the features of martensitic transformations. Of particular interest are the regular arrays of transformation dislocations which comprise the parenthydride interface and make for a very mobile interphase linkage. This focuses on the importance of certain types of dislocations which allow one phase to grow (and in a reversible manner) at the expense of another.

Results Expected, FY76: Thermodynamic analys 1s of the shape memory effect as related to "solid state engines" has Indicated the Importance of certain quantities of "design" Importance such as thermoelastic behavior, the transformation latent heat, parent phase flow stress, equ111brium temperature, and magnitude of recoverable strain. It is planned to measure these quantitles for a number of alloy systems to test the general validity of the analysis. It is further planned to make experimental efficiency measurements using a welght lifting device as constructed for the preliminary thermodynamic analysis.

With the recent purchase of a precision goinometrlc cooling stage for the transmission electron microscope, it is hoped to extend present research on lattice oscillations to a number of other materials exhibiting martensitic transformations at sub-ambient temperatures. With goniometric facilities (which were not avallable during the earlier work) it should be possible to relate lattice instabllitles to diffuse scattering in the electron diffraction patterns.

The work on hydrides Indicates the importance of characterizing interfacial dislocations in a quantitative manner. Contrast experiments w 111 be employed to determine Burgers vectors, and once accomplished, the implied glide planes will be examined with reference to the crystallographic theory of martensitic transformations. This should lead into new insights on modes of interface propagation.

Results Expected, FY77: Both experimental and theoretical work on the nature of the shape memory effect as related to energy conversion and other useful devices will be continued. By this time it is hoped that the work will have advanced to the point where cyclic behavior and "fat igue" life characteristics and other elements of dependability may be evaluated.

Assuming the eventual crystallization of certaln features of the premonftory lattice instabilities as deduced by electron microscopy and diffraction, it will be appropriate to use other techniques to verify or negate the findings. In this connection, some preliminary experiments have been made using the neutron facilities at the Brookhaven Laboratory. Conclusive results are yet to come, but the general direction of using other diffraction techniques including diffuse $x$-ray scattering and properties measurements (e.g., elastic constants) is indicated because of certain limitations intrinsic to thin film electron microscopy and diffraction.

Additional work on transformations in thin f1lms will be carried out, particularly with emphasis on the nucleation of solfd state reactions at imperfections. 
Research on hydride formation will be extended to other metals, and with the avaliablifty of a precision gonfometer stage for low temperature use, in sttu studies of hydride formation in thin films will be made. of particular importance w111 be the mode of interface propagation, and more detalled studies of the behavior of interface dislocations during phase growth.

Other Work: A' concurrent research program dealing with "Properties and Characteristics of Shape Memory Alloys" is belng supported by the National Science Foundation. This work deals with copper alloys and is with different emphasis. (Attempts are being made to resolve differences in behavior comparing internally twinned and internally faulted martensites in CuZn alloys). The present research on "solid state engines". also lends to the understanding of basic materfal properties involved in the shape memory effect. Work on the crystallography of hydride formation is $f$ undamentally related to possible energy storage, and supplements that at the Ames AEC Laboratory; both of these efforts are coupled with $x$-ray and metallographic work on hydrides being carrled out at the University of New South Wales. Equipment and techniques within the research program are being used in cooperation with work on oxidation and corrosion, also supported by the MRL at the University of Illinois. This program, primarily of a fundamental nature, couples with a parallel program of an engineering nature at the Lawrence Berkeley Laboratory. Some preliminary neutron diffraction experiments dealing with pretransformation lattice instabilities have been started in confunction with the Brookhaven Laboratory. Information is regularly exchanged during a weekly seminar, Met. E. 494, Solid State Phase Transformations.

Publications, Calendar Year 1974:

G. P. Asselin and C. M. Wayman

Nucleation and. Growth of Tungsten Films Evaporated on NaCl

physica status solidi (a). 24, 675-690 (1974)

C00-1198-1113

I. Cornelis, R. Oshima, H. C. Tong, and C. M. Wayman

Direct Observations of Pretransformation Lattice. Instab1lities

Scripta Metallurgica 8 , 133-144 (1974)

Co0-1198-1059

I. Cornelis and C. M. Wayman

Phase Transformations in Metastable $\beta$ " CuZn Alloys I: Martensitic

Trans formations

Acta Metallurgica 22, 291-300 (1974)

C00-1198-1000

I. Cornelis and C. M. Wayman

Phase Transformations In Metastable $B^{\prime}$ CuZn Alloys II: Isothermal

Trans formations

Acta Metallurg1ca 22, 301-311 (1974)

COO-1198-1001 
T. P. Darby and C. M. Wayman

Anomalous Diffraction Doublet from Gold Fllms on Graphite Substrates Philosophical Magazine 30, 1171-1175 (1974)

COO-1198-1101

T. P. Darby and C. M. Wayman

Growth of Gold Films on Alr- and Vacuum-Cleaved Molyb dentte

physica status solidi (a) $25,585-590$ (1974)

COO-1198-1133

H. C. Torig and C. M. Wayman

Characteristic Temperatures and Other Properties of Thermoelastic Martensites

Acta Metallurgica 22, 887-896 (1974)

CO0-1198-1021

H. C. Tong and C. M. Wayman

Direct Evidence of Pretransformation Lattice Instabilities

Physical Review Letters 32, 1185-1188 (1974)

Co0-1198-1067

H. C. Tong and C. M. Wayman

A Simplified Calorimeter for Determining Latent Heats of Martensitic

Transformations at. Low Temperatures

Metallurgica Transactions 5, 1445 (1974)

C00-1198-1061

H. C. Tong and C. M. Wayman

Some Stress-Temperature-Energy Relationships for Thermoelastic Martensitic Transformations

Scripta Metallurgica 8 , 93-100 (1974)

C00-1198-1022

H. C. Tong and C. M. Wayman

Thermodynamic Considerations of "Solid State Engines" Based on Thermo-: elastic Martensitic Transformations and the Shape Memory Effect

Metallurgical Transactions (submitted to)

C00-1198-1102

H. C. Tong and C. M. Wayman

Thermodynamics of Thermoelastlc Martensit1c Transformations

Acta Metallurgica (submitted to)

C00-1198-1064

M.S. Theses, Calendar Year 1974:

Gillis P. Asselin (C. M. Wayman, Adviser)

The Nucleation and Growth of Tungsten Th1n F1lms Vapor Deposited on VacuumCleaved Rock Salt Substrates

August 1973 (omitted from last year's report)

COO-1198-1152 
Yue-Kong Au (C. M. Wayman, Adviser)

Some Electrical Propertles of Amorphous Germanlum, Indium Antimonide and Gallium Antimonide F1lms

August 1974

COO-1198-1130

Terrence Alan Schroeder (C. M. Wayman, Adviser)

Shape Memory Behavior and Mechanical Charactertst1cs of Some Copper Zinc Alloys June 1974

C00-1198-1069

Ph.D. Theses, Calendar Year 1974:

Thomas P. Darby (C. M. Wayman, Adviser)

Nucleation and Growth of Gold Thin Films Vapor Deposited on Single Crystal

Graphite Substrates

May 1974

Co0-1198-1055 
NT-03-01-02-0 Mechanical Properties

Point Defect - Dislocation Interactions

Principal Investigator: Howard K. Birnbaum, Ph.D.

Professor of Physical Metallurgy

Supporting Agency: U. S. Atomic Energy Commission

Senfor Staff: Howard K. Birnbaum, Professor

C. Gregory Chen, Research Assoctate

Junior Staff: Joseph J. Au, Research Assistant

Gerald R. Matusiewicz, Research Assistant

Philip E. Zapp, Research Assistant

Object: To understand the basic diffusion mechanisms for hydrogen and its isotopes in bcc metals over a wide temperature range. Particular interest is directed towards understanding the role of trapping mechanisms in these processes. The local vibrational modes and coupling of hydrogen to the lattice are also of interest. We have been developing measurement techniques based on anelastic, magnetic relaxation and Raman methods to study these problems.

Interest in these problems arises from the abllity to study tunneling effects in light interstitial diffusion in great detall and from the importance of these physical processes in applied problems such as hydrogen embrittlement, stress corrosion, hydrogen isotope contalnment. These have a very wide applicability in both the fast breeder and fusion reactor programs.

Results, FY75: The increase of the $H$ and $D$ diffuston activation enthalpies with 0 trapping has been established over a range of compositions and temperatures. The isotope effects on the diffusive reorientation of $\mathrm{H}(\mathrm{D})$ in $\mathrm{Fe}$ has been established and the activation enthalpies for the relaxation processes in the $\mathrm{Fe}-\mathrm{D}$ system measured. The ordering of vacancies on the $H$ interstitial sublattice in off-stochlometric $\mathrm{NbH}$ has been shown and a new hydride structure determined (with Professor $H$. Fraser). The $\mathrm{Nb}-\mathrm{H}$ system has been shown to be Raman active and the Raman technique has been applied to studying the vibrational modes of H (with Professor M. Kle1n).

Results Expected, FY76: The techniques we have developed w111 be extended to studying hydrogen behavior in $\mathrm{V}$ and $\mathrm{Ta}$. Studles of the decomposition of the solid solutions in the $\mathrm{Nb}-\mathrm{H}$ system will continue using primarily electron microscopic techniques. The Raman methods will be applied to studies of the $\mathrm{Nb}-\mathrm{H}$ system near. the critical point. Elastic constant measurements will be used to study the spinodal decomposition of the solid solutions and the hydride precipitation in the Nb-H system. 
Results Expected, FY77: The studies Inftiated in FY 76 will be continued with the greatest emphasis on the studies of decomposition of the solid solutions using the TEM, Raman and elastic constant techniques. If support is available these methods could also be applied to studies of He behavior in metals. The use of these methods has been shown to allow a complete determination of the behavior of light interstitial solutes in bcc metals.

Other Work: This project is closely correlated with an ONR supported program on hydrogen embrittlement of bcc metals which is directed by H. Birnbaum. Part of the hydrogen behavior program is a foint effort with Professor $\mathrm{M}$. Klein (Raman spectroscopy of the $\mathrm{Nb}-\mathrm{H}$ system) and part is a cooperative effort with Professor Fraser (transmission electron microscopy studies of hydride precipitation). We also have a cooperative effort with the Sandia Laboratorles group headed by Dr. F. Vook (Albuquerque, N.M.) to apply lon channeling methods to study the site location of $\mathrm{D}$ and $\mathrm{O}$ in the $\mathrm{Nb}-\mathrm{O}-\mathrm{D}$ system.

Publications, Calendar Year 1974:

G. Matuslewicz, R. Booker, J. Keiser, and H. K. Birnbaum

On Gorsky Measurements of Hydrogen Diffusion in Niobium

Scripta Metallurgica 8, 1419-1426 (1974)

COO-1198-1105

G. J. Sellers, A. C. Anderson, and H. K. Birnbaum

The Anomalous Heat Capacities of Niobium and Tantalum below $1 \mathrm{~K}$

Physical Review B10, 2771-2776 (1974)

Also supported by the National Sclence Foundation

COO-1198-1076

R. F. Mattas and H. K. BIrnbaum

Isotope Effects on the Motion of $0-H$ Clusters in $\mathrm{Nb}$

Acta Metallurgica (submitted to)

C00-1198-1106

M.S. Theses, Calendar Year 1974:

None

Ph.D. Theses, Calendar Year 1974:

Richard Francis Mattas (H. K. Birnbaum, Adviser)

Low Temperature Internal Friction in the Nlobium-Hydrogen and Niobium-

Oxygen-Hydrogen Systems.

May 1974

C00-1198-1077 


\section{Deformation of Intermetallic Compounds at Elevated Temperatures}

Principal Investigator: Hamish L. Fraser, Ph.D.

Assistant Professor of Metallurgy

\section{Supporting Agency: U. S: Atomfc Energy Commission}

Senior Staff: Hamish L. Fraser, Assistant Professor

Junior Staff: Scott F. Hughes, Research Assistant

Nestor J. Zaluzec, Research Assistant

Object: The object of the research program falls into two parts. In the first case, the elevated temperature deformation mechanisms of $\langle 100\rangle$ crystals (hard crystals) of NiAl are being determined. The research is necessary to understand the mechanisms of deformation of the polycrystalline form of the compound. Previous work in this study has indicated that climb may be responsible for plastic deformation at elevated temperatures, and experiments involving transmission electron microscopy, measurements of lattice rotations and strain rate tests are being carried out to determine the role of climb.

The second part of the program concerns the prectpitation of hydrides in refractory metals. Experiments on hydrides in $\mathrm{Nb}$ and $\mathrm{Ta}$ are being carried out, involving both hydrides precipttated in bulk form, and those in thin foil. In situ experiments are planned using a working stage developed in the MRL. When appropriate stages are ready, in situ straining tests will be performed to study crack tip processes of pre-charged $\mathrm{Nb}-\mathrm{H}$ alloys. The results will be related to hydrogen embrittlement.

Results, FY75: On the work on NiAl, two important results have been achieved. Ffrstly, we have made a detalled study of the dislocations in deformed hard crystals. Three types of Burgers vectors have been observed, namely $\mathrm{b}=\langle 100\rangle,\langle 110\rangle$ and $\langle 111\rangle$. We have determined that those with $\underline{b}=\langle 11 \overline{0}\rangle$ and $\langle 111\rangle$ are formed by the Interaction of approprtate dislocations with $\underline{b}=\langle 100\rangle$. We conclude that these dislocations do not contribute to plastic deformation. Secondly, we have made a determination of the plane containing the Burgers vector and the line direction of many dislocations with $\underline{b}=\langle 100\rangle$ and have discovered that many have no rational slip planes. These observations are consistent with climb as $\dot{a}$ mechanism of plastic deformation.

Regarding the precipitation of hydrides, we have observed that the hydride of $\mathrm{Nb}$ precipitated in thin foll has an ordered structure. Transmission electron microscopy has revealed that the preclpttation of the hydride of $\mathrm{Ta}$ is accompanied by the punching of a number of prismatic dislocation loops. These loops have been analyzed and 1 t is found that they are interstitial in nature. This is consistent with the fact that the hydride precipltation involves an expansion of the lattice. 
Results Expected, FY76: Final experiments to determine the mechanisms of plastic deformation in hard crystals of NIAl compressed at elevated temperatures will be carried out. It is expected that these studies will reveal that climb of dislocations are indeed responstble for plastic deformation of hard crystals at high temperatures. The plasticity of soft crystals at high temperatures w1ll be examined in the light of the results expected for hard crystals.

The work involving precipitation of hydrides w1ll be extended to include in situ cooling experiments which will follow the hydride precipitation process. Concurrent to these experiments, stages will be designed to allow straining to be carrled out either in vacus or in an hydrogen environment inside the electron microscope. Inftial straining experiments on $\mathrm{Nb}-\mathrm{H}$ alloys will be performed to observe crack tIp processes and relate these to the problem of hydrogen embrittlement.

R.esults Expected, FY77: The work on NAAl will be extended to the important problem of understanding polycrystalline plasticity. The applicability of the results obtained on NiAl to other intermetallics will be examined. Hydride precipitation processes in refractory metals will be well characterized, both in bulk spectmens and in thin foll form. Straining experiments in the electron microscope should allow direct observations of the mechanism of hydrogen embrittlement in these metals.

Other Work: The work on hydride precipltation and hydrogen embrittlement is related to work belng carried out by Dr. H. K. Birnbaum and Dr. C. A. Wert in our MRI under AEC support. The program does not directly interact with other AEC work. However, there will be a close relation between the present work and that carried out by the principal investigators (in the Dept. of Metallurgy, U of I) of a NSF grant on hydrogen embrittlement of the iron-nickel-chromium system.

Publications, Calendar Year 1974:

Nestor J. Zaluzec and Hamish L. Fraser

The Origin of Dislocation th $\underline{b}=\langle 110\rangle$ in Single Crystals of $\mathrm{B}-\mathrm{N} f \mathrm{Al}$

Compressed Along $<001>$ at Elevated Temperatures

Scripta Metallurgica $\underline{8}, 1049-1054$ (1974)

C00-1198-1094

M.S. Theses, Calendar Year 1974:

None.

Ph.D. Theses, Calendar Year 1974:

None 
Deformation of Relnforced Metals

Principal Investigator: Marvin Metzger, Ph.D.

Professor of Physical Metallurgy

Supporting Agency: U. S. Atomlc Energy Commlssion

Senior Staff: Marvin Metzger, Professor

Junior Staff: Prabir R. Bhowal, Research Assistant

Object: To develop realistic models of matrix behavior at small strains in composite crystalline matertals and provide Information applicable to the design of technological materials contalning nondeforming phases. A central question in regard to the strength and ductility of these materials is the nature of the matrix interaction with the nondeforming phase during straining and the significance of the spacing of the latter. This is being studied in a $\mathrm{N1}_{3} \mathrm{Al}-\mathrm{NI}_{3} \mathrm{Nb}$ aligned eutectlc alloy, with the important features that interlamellar spacing can be varied and it can be thinned for electron microscopy.

Results, FY75: In this period, we expect significant results on the $\mathrm{NI}_{3} \mathrm{Al-N1} \mathrm{Nb}$ system at several interlamellar spacings including microyielding and macroylelding tests in tension at several temperatures and dislocation structure observations after sultable strains. These are expected to provide data for the identification of the appropriate type of model for the interaction of the matrix with the reinforcing phase (e.g., plastic constraint) and for crltical evaluation of speciflc models. Information on the intrinsic stress-strain behavior and dislocation structures of the $\mathrm{NI}_{3} \mathrm{Al}$ matrix phase is avallable from single crystal studies by other researchers.

Results Expected, FY76: In th1s perfod, we expect to complete study of the lower temperature range to $600^{\circ} \mathrm{C}$. The range of temperatures above this will then be examined as a supplementary project because the slip modes of the matrix are then different (and thus its interaction with the nondeforming phase is expected to change) and because the microstrain measurements important for evaluation of models will involve additional experimental difficulties.

Results Expected, FY77: We expect to continue in this area dealing with the factors determining matrix dislocation structure and the mechanical behavior of composites and considering posstble interactions between the matrix and the nondeforming phase both during testing and during preparation or when thermally cycled. Relatively few composites have been studied in detafl because of the difficulties in thinning many of these materials for microscopy, and much will remaln to be done. It will be necessary to examine selected materlals, chosen on the basis of the information developed by others and by ourselves, in which the desired $f$ undamental knowledge is experimentally accessible. 
Other Work: Current work. Involves coordination with the group at United Aircraft Research Laboratories, East Hartford, Conn., working on development of eutectic composite alloys for high temperature service (principal contact is Dr. F. D. Lemkey). They have supplied alloys together. with background information, and we remain in touch with them and will inform them of our results and models as they become avallable.

Pub11cations, Calendar Year 1974:

J. Zahavi and M. Metzger.

Breakdown of Films and Inftiation of Pits on Aluminum During Anodizing, Localized Corrosion

National Association of Corrosion Engineers 3, 547-555(1974)

Also supported by the U. S. Army Research of 1 fee (Durham)

CoO-1198-858

J. Zahav1 and M. Metzger

Effect of Chloride on Growth of an Anodic Film

Journal of the Electrochemical Soclety 121, 268-279 (1974)

Also supported by the U. S. Army Research Office (Durham)

C00-1198-1010

M.S. Theses, Calendar Year 1974:

None

Ph.D. Theses, Calendar Year 1974:

None 
The Mechanism of Stress-Corrosion Cracking: Propagation Studies

Principal Investigator: E. Neville Pugh, Ph.D.

Professor of Metallurgical Engineering

Supporting Agency: U. S. Atomic Energy Commission

Senior Staff: E. Neville Pugh, Professor

Junior Staff: Gerhardus H. Koch, Research Assistant

$\mathrm{J}$. Lawrence Nelson, Research Assistiant

Object: The fact that stress-corrosion cracking (SCC) has become a familiar and costly occurrence during the past few decades stems in part from lack of basic understanding of stress-corrosion phenomena, and, in broad terms, the object of this research is to provide mechanistic insight into the problem. Specifically, it has become focused on those failures which are thought to result from the entry of cathodically-generated hydrogen into the lattice. The view that hydrogen is responsible for a large number of stress-corrosion failures is still highly controversial and part of our effort is directed towards providing evidence for the hydrogen model. A second objective is to answer the numerous important questions related to the propagation of stress-corrosion cracks--is cracking continuous or discontinuous; if the latter, how far does the crack advance per propagation event and what is the frequency of crack advance: what is the orientation of the fracture surfaces?

Results, FY75: Studies of the transgranular SCC of an Mg-Al alloy in aqueous chloride - chromate solutions have demonstrated that the failure is due to hydrogen absorption. Work on this system was discontinued. in FY75 (but see plans for FY77), and attention was focused on $\alpha$-phase Ti alloys and Al- $\mathrm{Zn}-\mathrm{Mg}$ alloys, both of wh1ch undergo SCC in aqueous chloride solutions. In the case of $\mathrm{T} 1$ alloys, fractographic and acoustic-emission studies are in progress to compare the characteristics of crack propagation for speclmens undergolng slow crack growth in either the aqueous solutions or in dry gaseous hydrogen. Results to date support the view that the mechanism of embrittlement is the same in both environments. The most interesting result for the $\mathrm{Al}-\mathrm{Zn}-\mathrm{Mg}$ alloys was that limited amounts of discontinuous cleavage can occur during tensile testing in aqueous chlorides, laboratory alr and in several other moist gases. This type of fallure was not observed in tests at high strain rates or in dry gases, suggesting that cleavage results from the entry of hydrogen generated by reaction of water with aluminum. Limited studies on a type-304 stainless steel ylelded the interesting new result that slow crack growth occurs when the alloy is stressed in gaseous hydrogen. Significantly, the resulting fracture surfaces were similar in appearance to those produced by the transgranular SCC of this material in hot aqueous chlorides. 
Results Expected, FY76: It is anticlpated that research during this period will consolidate the view that SCC in both $\alpha-\mathrm{Tl}$ and Al alloys is a form of hydrogen embrittlement. In the $\alpha-\mathrm{T} i$ case, studles are in progress to determine whether the orientations of the transgranular fracture surfaces produced by slow crack growth in aqueous $\mathrm{NaCl}$ and gaseous hydrogen are the same. Experiments are also being carried out on particles extracted from the fracture surfaces of $\alpha-T 1$ specimens tested in gaseous hydrogen. Preliminary electron-diffraction data Indicate that the particles consist. of a titanlum hydride and this observation may prove to be relevant to the proposal that hydrogen embrittlement involves the formation of massive hydrides.

Results Expected, FY77: While it is necessary to establish that SCC in a number of systems occurs by hydrogen-induced brittle fracture, it does not answer the more fundamental question of the role of hydrogen. One possibility is that it leads to the formation of a brittle hydride at the crack tip, and this will be pursued by means of transmission electron microscopy of folls contalning hydrogen. It is probable that these experiments w111 be initiated in Mg-Al alloys and that they will be carried out in cooperation with H. L. Fraser. Another posstble area of future study concerns other embrittling specles. The occurrence of hydrogen-related fallures in a wide varlety of materials presumably stems from the fact that hydrogen is present in commonly encountered environments and also because it is highly mobile in metals at amblent temperatures. However, there is no reason to suspect that certain other species would not cause simflar embrittlement if they were present in sufficlent concentration and if they were sufficiently mobile. The fallure of $\mathrm{Zr}$ alloys in iodine vapor at elevated temperatures has similar characteristics to the room-temperature hydrogen embrittlement of the $\mathrm{HCP} \mathrm{Mg}-\mathrm{Al}$ and Ti-Al alloys, and, by analogy, it might be instructive to examine fractured specimens for the presence of fodide compounds.

Other Work: The phenomenon of hydrogen embrittlement is also being studied by H. K. Birnbaum (in $\mathrm{Nb}$ ) and, whlle there is useful interaction between the two programs, there is no overlap or duplication of effort. Beginning in the summer of 1975, the Principal Investigator, sharing a research assistant or post-doctoral fellow with C. J. Altstetter, will take part in an NSF-funded study of SCC and hydrogen embrittlement of austenitic stainless steels; this is part of a larger program on the hydrogen embrittlement of $\mathrm{Fe}-\mathrm{Ni}-\mathrm{Cr}$ alloys (with H. K. Blrnbaum, H. L. Fraser and $R$. A. Yeske). In addition to hydrogen-induced cracking (usually transgranular), a second class of stress-corrosion failures exists which is thought to involve the stress-assisted penetration of grain boundarles by a brittle oxide film, e.g. the intergranular SCC of $\mathrm{Cu}$ alloys, mild steels, and austenitic stainless steels (in hot pure water). This type of SCC is being investigated by the Principal Investigator (and two research assistants) under an ARO grant. 
Publications, Calendar Year 1974:

D. G. Chakrapani and E. N. Pugh

On the Fractography of Transgranular Stress-Corrosion Fallures in a Mg-Al Alloy

Corrosion (submitted to)

c00-1198-1107

D. G. Chakrapan1 and E. N. Pugh

The Transgranular SCC of a Mg-Al Alloy: Crystallographic, Fractographic and Acoustic-Emission Studies

Metallurgical Transactions (submitted to)

C00-1198-1104

M.S. Theses, Calendar Year 1974:

H. Gabel (E: N. Pugh, Adviser)

An Electron Microprobe Study of the Composition of Tarnish Films on Copper-Zinc, Copper-Aluminum, and Copper-Nickel Alloys January 1974

Also supported by the U. S. Army Research offlce (Durham) COO-1198-1139

Ph.D. Theses, Calendar Year 1974:

None 
Precipltation in Refractory Metal Alloys

Princlpal Investigator: Charles A. Wert, Ph.D.

Professor of Physical Metallurgy;

Head, Department of Metallurgy and Mining Engineering

Supporting Agency: U. S. Atomfc Energy Commlssion

Senior Staff: Charles: A. Wert, Professor

Edwin L. Pollock, IBM Postdoc Fellow and Research Associate

Junior Staff: Robert W. Levis, Research Assistant

Theodore R. WIlken, Research Assistant

Object: To study alloys of the metals $\mathrm{V}, \mathrm{Nb}$ and $\mathrm{Ta}$ with the interstitials hydrogen and carbon. Both the solld solutions of hydrogen and deuterium. in these metals are to be investigated and the properties of the hydrides and deuterides. The characteristics of carbides of $\mathrm{V}$ and $\mathrm{Nb}$ in these metals is to be examined by electron microscopy, espectally of the mixed carbides such as $\mathrm{V} T 1 \mathrm{C}_{\text {}}$ and $\mathrm{V} \mathrm{Cr}_{\mathrm{C}} \mathrm{C}$. The strengthening effects of these carbides will be getermined. These studies are basic metallurgical studies of the thermodynamic, kInetic and crystallographic features of these alloys. Since these metals are likely candidates for structural members of nuclear and fusion reactors, they are related to practical applications of the alloys.

Results, FY75: (1) We have determined rates of formation of hydrides and deuterides in. Ta and V. Small amounts of oxygen have been found to retard, greatly, formation rates of these compounds. Thermodynamic and kinetic parameters seem well established for the $\mathrm{Ta}-\mathrm{H}$ and $\mathrm{Ta}-\mathrm{D}$ systems as well as for these binaries with $1 \%$ of oxygen present. For vanadium, our own results are internally consistent, but differ somewhat from those of Westlake at Argonne. (2) We have completed an Initial study of the carbides formed in the ternary system $\mathrm{V}-\mathrm{TI}-\mathrm{C}$. The mixed carbide forms small thin platelets on the (310) planes of the metal. They are stable to temperatures over $1000^{\circ} \mathrm{C}$, whereas simflar platelike carbides in the $\mathrm{V}-\mathrm{C}$ blnary alloys become unstable above $400^{\circ} \mathrm{C}$. (3) Initial stages of work involving tungsten will be completed (see 1977).

Results Expected, FY76: (1) We will conclude the work on the V-H and $\mathrm{V}-\mathrm{D}$ systems to eliminate the small, but slgnificant, differences between our work and those of Westlake. (2) We will extend our study of the electron microscopy of the hydrides and deuterides of vanadium. This study will be shared with Hamish Fraser and w11l be correlated with similar work of Fraser and Blrnbaum in $\mathrm{Nb}$ and of Fraser in Ta. (3) We will begin a detalled electron microscope study of carbides in the V-TI-C alloy system, building on the brief study so far carried out. We will determine kinetics of mixed-carbide formation, temperature range of stability of the carbide and strengthening effects assoclated with formation of the carbide. 
Results Expected, FY77: Three pleces of work are planned. (1) Investigation of the alloy systems $V-T I-C-H$ and $V-T I-C-D$. If carbide-hardened refractory metals are to be used as structural members in reactors, we need to know. their characteristics in the presence of hydrogen and deuterium. While embrittlement effects might not be a problem at high temperatures, they could be important at low temperatures. (2) Electrontc and magnetic effects of $\mathrm{H}$ and $\mathrm{D}$ in $\mathrm{V}, \mathrm{Nb}$ and $\mathrm{Ta}$. Changes in paramagnet $1 \mathrm{c}$ moment accompanying hydrogen and deuterium additions to these metals w1ll be made (see below). Understanding of the electronic nature of the dissolved atoms is the goal. (3) Void hardening of the refractory metals. We are carrying on a small study of the role of $\mathrm{K}, \mathrm{Al}$ and $\mathrm{Si}$ additions in hardening of tungsten (as for lamp filaments). The hardening mechanism seems to be formation of arrays of "voids" produced in the metal by superheating of small particles of a potassium compound carried along through the powder-metallurgy production of tungsten B-metal. This process, developed through some 50 years in the lamp industry, may have applicability in other refractory metals. We propose to try it for $\mathrm{Nb}$. We w11l $\mathrm{mlx}$ powders of niobium oxdde with additions of small amounts of $\mathrm{KOH}, \mathrm{Al}_{2} \mathrm{O}_{3}$ and $\mathrm{SIO}_{2}$. We will at tempt to reduce this oxide mixture to $\mathrm{Nb}$ powder containing a small amount of potassium which might be carried along to production, by sintering, of a Nb rod. We will attempt to produce arrays of volds filled with K-vapor by proper wire drawing and heating treatments. Such voids might control recrystallization of the $\mathrm{Nb}$ in such a way as to produce destrable high temperature mechanical properties.

Other Work: We are carrying on a program of measurement of changes in elastfc constants of $\mathrm{V}, \mathrm{Nb}$ and $\mathrm{Ta}$ which accompany additions of hydrogen in solid solution. This work, supported by the NSF grants program, is being carried out in conjunction with staff of the Sclence Center, Rockwell International. Because of legal restrictions assoclated with my presence on the staff of NSF, the work ts held up, perhaps until the summer of 1976. During this interval, a group at Argonne and a group at Munich will go far ahead of us. Therefore, we propose a study in which we have an edge--the correlation of changes in paramagnetic susceptibility with changes in elastic constants accompanying hydrogen (and deuterium) addition to these metals. A theory has been proposed by a Swiss theortst that these changes should be related in this way.

$$
\frac{\partial \Delta C_{i j} / C_{i j}}{\partial T}=A+B \frac{\partial \Delta x / x}{\partial T}
$$

The $\Delta C_{1 j}$ and $\Delta x$ are changes produced by the hydrogen addition. If all of this ${ }^{1}$ works, we will be able to correlate changes in electrontc structure of the solid solution with changes in elastic constants. A troublesome anomaly seen by us (and our competitors) in changes in the $C_{i j}$ might be understood.

Work on phase diagrams of the $\mathrm{V}-\mathrm{H}$ and $\mathrm{V}-\mathrm{D}$ systems is being correlated with that of Don Westlake of Argonne by frequent visits, exchanges of results and exchanges of samples. 
Pub11cations, Calendar Year 1974:

H. Y. Chang, R. K. Viswanadham, and C. A. Wert Age Hardenfing in the $\mathrm{V}-\mathrm{C}$ and $\mathrm{Nb}-\mathrm{C}$ Systems

Metallurgical Transactions 5; 1907-1917 (1974)

CO0-1198-1079

H. Y. Chang and C. A. Wert

Precipitation of Carbides in Deformed Vanadium

Metallurgical Transactions $\underline{5}, 1671-1676$ (1974)

CoO-1198-1078

B. Ganguly, C. Wert, and J. Woodhouse

Microchemistry of Copper-Infiltered Iron Powder

International Journal of Powder Metallurgy 10, 87-99 (1974)

COO-1198-990

J. E. Greene, J. Woodhouse, and M. Pestes

A Technique for Detecting Critical Loads in the Scratch Test for Thin Film Adhesion

The Review of Scientific Instruments 45, 747-749 (1974)

Also supported by JSEP DAAB-07-72-C-0259

COO-1198-1095

R. K. Viswanadham and C. A. Wert

Precipitation from Super-Saturated $\mathrm{Nb}-\mathrm{C}$ Solid Solutions

Metallurgical Transactions $\underline{5}, 123-126$ (1974)

C00-1198-968

J. B. Woodhouse, A. L. A. Flelds, and I. A. Bucklow

$X$-ray. Mass Absorption Coefficients for Gold, Lead and Bismuth in the Range $1 \AA$ to $10 \AA$

Journal of Physics D: Applied Physics $\underline{7}, 1483-1489$ (1974)

CO0-1198-1002

M.S. Theses, Calendar Year 1974:

Christian Paul Fluhr (C. A. Wert, Adviser)

An Electron Microscopy Study of Carbide Preclpitation in a VanadiumTitanium Alloy

May 1974

C00-1198-1081

Ph.D. Theses, Calendar Year 1974:

Phillppe Lecocq (C. A. Wert, Adviser)

The Solubility of Hydrogen in Tantalum

October 1974

C00-1198-1128 
NT-03-01-03-0 Physical Properties

Interstitial Solid Solutions

Princtpal Investigator: Carl J. Altstetter, Sc.D.

Professor of Physical Metallurgy; Acting Head, Department of Metallurgy

Supporting Agency: U. S. Atomic Energy Commission

Senior Staff: Carl J. Altstetter, Professor

Junior Staff: Gary L. Steckel, Research Assistant

Peter F. Tortore11i, Research Assistant

Object: The study of bcc refractory metals is undertaken because their attractive high temperature, corrosion and nuclear properties make them candidates for future fission and fusion reactor structural materials. We are investigating their baslc physical metallurgy and, in particular, their solid solutions with the atmospheric gases, which can cause severe degradation of properties. Of equal importance is their relatively high solubility for these gases, so that they make ideal models from which much can be learned about bcc metal - Interst1tlal solute interactions - solubility, ordering, precipitation, mechanical properties, etc. We study, to a large extent, oxygen and nitrogen in the group $\mathrm{V}$ metals ( $\mathrm{V}, \mathrm{Nb}$ and $\mathrm{Ta}$ ). Three projects are underway: a) work hardening in vanadium containing dispersions of $V_{16} \mathrm{~N}$ platelets (mechanfcal properties, electron microscopy), b) Ehermodynamic properties and solubility of oxygen in vanadium and in $\beta-V_{0} O$ (emf of solid galvanic cells), c) effect of solute and precipitate distributions on sputtering by energetic lons (ion beam Irradiation, welght loss, scanning electron microscopy, Auger spectroscopy).

Results, FY75: a) The study of dispersion strengthening has been completed. There have been three major accomplishments: derivation and application of expressions for quantitative electron metallography of thin foils containing large platelet precipitates. Verification for the first time of Ashby's theory of work hardening in a bcc dispersion strengthened material. Demonstration of basic differences in dislocationparticle interactions in $f c c$ and bcc matrices. b) The emf technique has been successfully extended from the $\mathrm{Nb}-\mathrm{O}$ and $\mathrm{Ta}-0$ to the more complicated V-O system. Preliminary data have been obtalned. c) The fon accelerator is nearly assembled. Preliminary experiments have been done on existing equipment, with good reproduction of published results.

Results Expected, FY76: In this year we w11l complete our study of the $V-0$ system and apply the emf technique to ternary refractory metal alloys containing varfous substitutional solutes, both active and passive with regard to oxygen interaction. Oxygen diffusion measurements will also be made in binary and ternary systems. In the sputtering 
experiments the equipment should become fully operational in the period. It is expected that both single phase (e.g. stalnless steel) and two phase (e.g. $\mathrm{V}-\mathrm{V}_{16} \mathrm{~N}$ ) materials w111 be examined.

Results Expected, FY77: In th1s year Mr. Steckel w111 have finished his Ph.D. thesis on oxygen in binary and ternary alloys. It is expected that we will then begin to use thin layers of metals and electrolyte for low temperature measurements of oxygen potential. Measurements of the potential of other species, e.g. carbon, will also be begun. Sputtering at elevated temperature will be carrled out and the effects of solute and microconstituent redistribution w111 be investigated. Alteration of mechanical behavior will be evaluated.

Other Work: Close contact has been maintained with Donald Potter of Argonne National Laboratory. It is proposed that sputtering experiments be carried out at Argonne using the dynamitron heavy ion accelerator. We are still courdinating the emf work with the Max Planck Institut, Stuttgart, Germany, the only other group with objectives similar to ours. Under NSF sponsorship, a cooperative effort with Birnbaum, Fraser, Pugh and Yeske on hydrogen embrittlement mechanisms in fcc materlals has begun. NSF funding of the cooperative program between Wert and $I$ and sclentists at the University of Tokyo has expired, but the cooperation continues. No duplication of ef fort exists in these endeavors.

Publications, Calendar Year 1974:

None

M.S. Theses, Calendar Year 1974:

None

Ph.D. Theses, Calendar Year 1974:

None 
Nuclear Magnetic Resonance Studies

Principal Investigator: Theodore J. Rowland, Ph.D.

Professor of Physical Metallurgy

Supporting Agency: U. S. Atomic Energy Commission

Senior Staff: Theodore J. Rowland, Professor

Junfor Staff: Lance C. Labun, Research Assistant

Patrick M. Lenahan, Research Assistant

Robert S. Shalvoy, Research Assistant

Patricia A. Birnbaum, Graduate Fellow

Object: To measure the diffusivity of hydrogen in dilute solution in niobium and to determine the effects of oxygen and nitrogen on the hydrogen jump frequency. Knowledge of hydrogen diffusion and trapping is important to many possible uses of niobium as a shielding or cladding material in hydrogen bearing or aqueous environments.

Nuclear relaxation is also being measured in crosslinked polymeric solids. As an important measure of molecular segmental motion this should correlate with the time and temperature dependent mechanical properties of these solids and contribute to the interpretation of mechanical properties in terms of molecular structure.

Results, FY75: The precipitation of CuBe from a $\mathrm{Cu}-2$ wt \% Be age hardening alloy was followed using nuclear magnetic resonance to monftor the matrix composition. Field Ion microscopy was used to corroborate particle size estimates and show that lattice distortion surrounding the precipitate particles appreciably diminished the resonance amplitude.

A variable temperature, single coil rig capable of $\mathrm{T}_{1}$ measurements by the tone burst technique is nearing completion. " Data w1li be used to determine the jump frequency of hydrogen diffusing in niobium. Progress in specimen preparation also has been made.

Relaxation time $T_{1}$ has been measured as a function of temperature for several specimens of polybutadiene differing in crosslink density. Sample preparation problems have been overcome and clean, chemically well-characterized samples are now ylelding systematic data.

Results Expected, FY76: Many of the practical uses of nlobtum involve the diffusion of hydrogen through essentially pure nloblum whe reas most diffusion studies have been of the hydride phases. By measuring the proton spin-lattice relaxation time in dilute solutions of hydrogen in $\mathrm{Nb}$ at a number of temperatures, we intend to derive the proton jump f requencles and activation energy for diffusion. These data enter importantly into the use of niobium in a hydrogen bearing or aqueous environment. 
With regard to the Investigation of cross 1inked polymers, our goal will be to establish a systematic correlation of network molecular chain length and chain length distribution with nuclear relaxation and thus network vibrational frequencies. We will attempt to associate the latter with the time dependent mechanical properties of these three dimensional amorphous networks.

If progress in other areas is satisfactory, work on concentrated alloys, and specifically phase transitions in some transition metal alloys is to begin. We will look for the periodic spactal charge distribution hypothesized to exist, and for evidence of fluctuations with time within temperature regions where the phases are metastable.

Results Expected, FY77: The diffusion of hydrogen in transition metals and their alloys is a subject of great and continuing importance. We will extend our studies to other systems of fundamental and/or practical interest, and also to the effects of interstitlal impurities such as oxygen and nitrogen in trapping hydrogen. In these instances resonance techniques are particularly useful because they are insensitive to surface diffusion, and because they measure a different quantity than chemical diffusion experiments, namely, the jump frequency rather than the mass flux. This distinction is especlally slgnificant when trapping is involved.

Information relevant to the omega phase transformation and phase stability in $\mathrm{Nb}-\mathrm{Zr}$ will be obtained; this unusual metastable phase appears to be one in which electronic configuration and mechanical (elastic-plastic) instabilities are related in a manner amenable to theoretical analysis.

Other Work: This group participates in more or less continuous correspondence and discussion with other researchers here and at other laboratories. These contacts are of a mutually useful and helpful nature both in the specific areas discussed above and those outslde of our Immediate concern.

Publications, Calendar Year 1974:

None

M.S. Theses, Calendar Year 1974:

None

Ph.D. Theses, Calendar Year 1974:

Andrew Chien-Chong Yen ( $T$. J. Rowland, Adviser)

A Study of Precipitation in Copper +13 Atomic Percent Beryllium by Nuclear Magnetic Resonance and Field Ion Microscopy

June 1974

C00-1198-1073 
SOLID STATE PHYSICS

NT-03-02-02-0 Experimental Research

Use of Very High Pressure to Investigate the Structure of Matter

Principal Investigator: Harry G. Drickamer, Ph.D.

Professor of Chemical Englneering and of

Physical Chemistry

Member, Center for Advanced Study

Supporting Agency: U. S. Atomlc Energy Commission

Senior Staff: Harry G. Drickamer, Professor

Junior Staff: Kevin Bieg, UI Fellow

William D. Drotning, Research Assistant

Erlc Hockert, UI Fellow

John W. Hook III, Teaching Assistant

Gary L. House, Research Assistant

David I. Klick, Research Assistant

Dean J. Mitche11, Research Assistant

Cralg E. Tyner, NSF Fellow

Doug Wilson, NSF Fellow

Object: The purpose of this project is the Investigation of the electronic behavior of solids, using very high pressure as a primary tool.' Present experimental techniques permit optical absorption and luminescence measurements to 160 kilobars, electrical resistance studies to $500 \mathrm{kllobars,} \mathrm{x}$-ray diffraction measurements to $400 \mathrm{kflobars,} \mathrm{and} \mathrm{Molssbauer} \mathrm{resonance} \mathrm{studies}$ to 250 kilobars.

Our approach is to study the relative displacement of one set of orbitals with respect to another as pressure increases. From such studles we can evaluate the parameters describing the ground state and excited state potential wells. Under many circumstances we observe an electronic transt tion to a new ground state whose properties we can also evaluate.

Projects currently active include studies of optical absorption and luminescence of impurities in alkall halldes, $\mathrm{ZnS}$ phosphors, oxygenated phosphors and organic crystals, as well as photochromism and photochemistry in sp1ropyrans, anfls and titanates. The object 1s to develop more efficient optical materials through a better understanding of electronic excltation and energy transfer in condensed systems. 
Results, FY75: (1) We have made a thorough study of optical absorption and luminescence of organic molecules (anthacene, phenanthrene, purine and pyrimidine bases and nucleosides) In the crystalline state, in polymers and in solution. By an extension of the Drickamer-Slichter treatment we have characterized these excltations in a new and useful way. (2) We have made a thorough study of high pressure photochromism and plezochromism in bianthrones and analyzed the results. (3) High pressure luminescence studies have been Inttlated in doped alkall halldes, In $\mathrm{ZnS}$ phosphors, and in oxygenated phosphors. (4) We have initiated high pressure photochromlc studies on anils and spiropyrans. (5) We have completed a detalled study of the effect of pressure on the electronic structure of several ferrites and orthoferrites.

Results Expected, FY76: (1) We expect to carry nearly to completion our study of alkali halide phosphors including photost1mulated luminescence. (2) We expect to make very significant progress in our luminescence studies of $\mathrm{ZnS}$ and oxygenated phosphors. (3) We expect to make extensive progress on our studies of photochromism and plezochromism in antls and spiropyrans and inftiate work on doped t1tanates. (4) We plan to have our thermoluminescence apparatus in operation. (5) We plan to initiate studies of energy transfer in phosphors. (6) We plan to inftlate studles of NMR under extreme conditions jointly with J. Jonas. (7) We plan to continue collaboration with C. P. Slichter and G. Weber.

Results Expected, FY77: Over the long range we plan to use high pressure spectroscopic methods to investigate the electronic structure of condensed phases and to provide the basic understanding for development of better materials. The tools include optical absorption and luminescence, thermo1 uminescence, photochromism and plezochromism and NMR. Extensions of our 1 uminescence studies include rare earth fons in varfous environments, polymers and blological materials, and measurements of lifetimes of excited states. We plan to extend our plezochromism to include inorganic compounds. We plan to infitate studies of photochemical reactions in transition metal compounds and in polymers. We are constdering also the study of pressure effects on light-emfting diodes.

Other Work: There is a wide variety of high pressure phystcs in the $12 \mathrm{kbar}$ range, and some physics and geophysics in the $100 \mathrm{~kb}$ ar range. There are no other laboratories doing consistent studies of electrontc phenomena in the range to several hundred kllobars in the U.S. Work of this kind is initiating in Japan and Russia. Interactions outside the Untversity Involve informal discussions on techniques and interpretation with people like George Samara, Sandia Laboratories; William Daniels in Physics at the Unfversity of Delaware; William Dauben, an organic chemist at the University of Calffornia, Berkeley; Denis McWhan and A. Jayaraman at Bell Labs, etc. There is also a continuing interaction with laboratories in Germany, Japan, and France. Interactions at Illinols include continuing cooperation with C. P. Slichter in Physics on the characterization of electronic transitions, cooperation with G. Weber in Biochemistry and Biophysics on high pressure fluorescence of blologically active molecules, and with $\mathrm{J}$. Jonas on NMR under extreme conditions. 
Publications, Calendar Year 1974:

H. G. Drickamer

Electronic Transitions In Transition Metal Compounds at High Pressure Angewandte Chemie 13, 39-47 (1974)

C00-1198-976

D. L. Fanselow and H. G. Drickamer

High Pressure Studies of the Electronic Behavior of Bianthrones

Journal of Chemical Physics 61, 4567-74 (1974)

C00-1198-1080

N. A. Halasa, G. DePasquali, and H. G. Drickamer

High Pressure Studies of Ferrites

Physical Review B10, 154-164 (1974)

C00-1198-1028

S. H. Moon and H. G. Drickamer

The Effect of Pressure on Hydrogen Bonds In Organic Solids

Chemlca1 Physics 61, 48-54 (1974)

COO-1198-1062

B. Y. Okamoto and H.:G. Drickamer

High Pressure Studies of Solvent Effects on Anthracene Spectra

Proceedings of the National Academy of Sclences 71, 47.57-4759 (1974)

COO-1198-1097

B. Y. Okamoto and H. G. Drickamer

The Evaluation of Configuration Coordinate Parameters from High Pressure Optical Data I: Phenanthrene, Anthracene and Tetracene

Journal of Chemical Physics 61, 2870-2877 (1974)

C.00-1198-1074

B. Y. Okamoto and H. G. Drickamer

The Evaluation of Configuration Coordinate Parameters from High Pressure Optical Data II: Purlne and Pyrimidine Bases and Nucleosides

Journal of Chemical Physics 61, 2878-2882 (1974)

C00-1198-1072

B. Y. Okamoto, W. D. Drotning, and H. G. Drickamer

The Evaluation of Conflguration Coordinate Parameters from High Pressure Ab sorption and Luminescence Data

Proceedings of the National Academy of Sclences 71, 2671-2674 (1974)

C00-1198-1071

Gregorio Weber, Fumio Tanaka, Byron Y. Okamoto, and H. G. Drickamer The Effect of Pressure on the Molecular Complex of Isoalloxazine and Adenine

Proceedings of the National Academy of Sclences $71,1264-1266$ (1974)

CoO-1198-1033 
H. G. Drickamer

The Effect of Pressure on the Electronic States of Organic Solids

Proceedings of the International Conference on Organic Synthesis, Belgium, August 26-30, 1974. (submitted to)

COO-1198-1083

\section{M.S. Theses, Calendar Year 1974:}

D. L. Woracek (H. G. Drickamer, Adviser)

Effects of Pressure on Alkall Halldes Doped with Lead (II)

June 1974

Ph.D. Theses, Calendar Year 1974:

Dan L. Fanselow (H. G. Drickamer, Adviser)

The Effect of High Pressure on a Series of Photochromic, Thermochromic and Piezochromic Bianthrones

October 1974

Nicholas Allen Halasa (H. G. Drickamer, Adviser)

Hyperfine Interactions in. Ferrites and Orthoferrites at High. Pressure February 1974

COO-1198-1031

Sang Heup Moon (H. G. Drickamer, Adviser)

High Pressure Studies on Hydrogen Bonding in Solids

May 1974 
Anharmonic Effects in Solids

Principal Investigator: Andrew V. Granato, Ph.D.

Professor of Phystes

Supporting Agency: U. S. Atomic Energy Commission

Senior Staff: Andrew V. Granato, Professor

Ricardo B. Schwarz, Visiting Assistant Professor

Junior Staff: Terrel1 D. Berker, Research Assistant

Randa11 D. Isaac, Research Assistant

David L. Johnson, Research Assistant

David B. Poker, Research Assistant (Beginning 1/6/75)

David L. Read, Research Ass1stant (Unt11 1/5/75)

Object: We have been engaged in a program of understanding the non-11near elastic properties of materials of systematically increasing complexity. We propose now to use results previously found for materlals of different bonding types and crystal structures in applications to studies of thermal properties, mechanical strength, and defects in crystals.

Results, FY75: (1) Dislocation resonance was found in lead at $4.2 \mathrm{~K}$ in both the normal and superconducting state. (2). A theory of ultrasonic stress-blas effects was given and tested. Prevlously given theorles were found to be invalid. (3) A method of measuring dislocation segment length distribution function was devised. (4) It was demonstrated that the force-distance profile between a dislocation and a single point defect can be determined from amplitude dependent dislocation damping measurements.

Results Expected, FY76: (1) Studies of resonance modes in metals using elastic constant measurements on irradiated specimens: (2) Configuration of hydrogen in metals from elastic constant measurements. (3) Ultrasonic studies of the mechanical strength of superconductors.

Results Expected, FY77: (1) Point defect interactions with 1mpurities. (2) Effects of dislocation inertia on the strength of metals: (3) Application of finite elasticity theory to properties of crystals containing defects.

Other Work: We are cooperating with Jon Holder of MRL on experiments to determine the symmetry of free interstitials and close-patrs in metals by use of elastic constant measurements.

Publications, Calendar Year 1974:

E. R. Fuller, Jr., A. V. Granato, J. Holder, and E. R. Nalmon Ultrasonic Studies of the Properties of Solids Solid State Volume of METHODS OF EXPERIMENTAL PHYSICS, edited by R. V. Coleman (1974), p. 371.

Also supported by the National Sclence Foundation and the Advanced Research Projects Agency

COO-1198-906 
E. R. Fuller, Jr. and W. F. Weston

Relation Between Elastic-Constant Tensors of Hexagonal and Cubic Structures Journal of Applied Physics 45, 3772-3776 (1974)

C00-1198-1065

J. Holder, A. V. Granato, and L. E. Rehn

Effects of Self-Interstitials and Close Palrs on the Elastic Constants of Copper

Physical Review B10, 363-375 (1974)

Also supported by the National Sclence Foundation

C00-1198-1038

J. Holder, A. V. Granato, and L. E. Rehn

Experimental Evidence for Split Interstit1als in Copper

Physical Review Letters 32, 1054-1057 (1974)

Also supported by the National Sclence Foundation

C00-1198-1034

L. E. Rehn, J. Holder, A. V. Granato, R. R. Coltman, and F. W. Young, Jr. Ef fects of Thermal Neutron Irradiation on the Elastic Constants of Copper Physical Review B10, 349-362 (1974)

Also supported by the National Science Foundation

C00-1198-1035

J. A. Garber and A. V. Granato

Fourth-Order Elastic Constants and the Temperature Dependence of SecondOrder Elastic Constants in Cubic Materials

Physical Review (submitted to)

c00-1198-1092

J. A. Garber and A. V. Granato

Theory of the Temperature Dependence of Second-Order Elastic Constants

in Cubfc Materials

Physical Review (submitted to)

C00-1198-1091

K. D. Swartz, W. Bensch, and A. V. Granato

The Second, Third, and Fourth Order Elastic Constants of Beta Brass

Physical Review (submitted to)

C00-1198-1016

M.S. Theses, Calendar Year 1974:

None

Ph.D. Theses, Calendar Year 1974:

Lynn Eduard Rehn (J. Holder, de facto Adviser and A. V. Granato, de jure Adviser)

Contributions from Point Defects to the Elastic Constants of Copper Also supported by the National Sclence Foundation

February 1974

COO-1198-1036 
Defect and Electronic Properties of Solids

Principal Investigator: David Lazarus, $\mathrm{Ph} . \mathrm{D}$.

Professor of Physlcs

Supporting Agency: U. S. Atomlc Energy Commission

Senior Staff: David Lazarus, Professor

John P. Bensel, Research Associate

Junior Staff: Paul C. Allen, Research Assistant

Gennghmun Eng, Research Assistant

Mark S. Jackson, Research Assistant

Arthur E. Pontau, Research Assistant

Object: Experimental and theoretical studies are undertaken to investigate the defect and electronic properties of classic prototype solids as a function of hydrostatic pressure and temperature to determine the basic atomic mechanisms which enter into mass, charge, and thermal transport in a wide variety of materfals. Particular emphasis is placed on studies of diffusion mechanisms, thermoelectric properties, and fluctuations in electrical noise near phase transitions.

Results, FY75: Work has been completed on a study of co-diffuston of trace impurities in $\mathrm{NaCl}$ crystals and an improved theoretical model has been developed. Work is nearing completion on construction of electronic apparatus, furnaces, and cryostats to permit investigations of electrical noise in solids over a wide range of temperatures. Studies of the isotope effect for tin diffusing in titantum are nearing completion. Studies of "superionfc" conductors have been begun, with the major emphasis to date on preparation of single crystal spectmens of $\mathrm{AgI}$ and $\mathrm{Ag}_{4} \mathrm{RbI}_{5}$.

Results Expected, FY76: Work should be completed on the 1sotope effect for diffusion in titanium. Conductivity and tracer diffusion studies, as well as notse measurements, of the superionic silver lodides should be underway to investigate the defect behavior of these systems as functions of temperature and pressure.

Results Expected, FY77: Studies of superionic conductors w111 be extended to other systems to ascertain simflarities and differences in transport mechanisms. Other new, related programs will be initiated.

Other Work: None of our work directly duplicates work done elsewhere. Largely through correspondence, meetings, and exchange of preprints, we maintain close contact with other groups studying related problems. Studies of superionic conductors are carried out in close collaboration with Professors W. Flygare, M. Kleln, W. McMillan, and M. Salamon of MRL who are investigating other properties of these materials. 
Publications, Calendar Year 1974:

R. S. Hockett and David Lazarus:

Search for Magneto-Flicker Noise in $\mathrm{K}$

Physical Review B10, 4100-4111 (1974)

C00-1198-1084

Jonathon D. Weiss and D. Lazarus

Pressure Dependence of the Thermoelectric Power of Sodium Between $5^{\circ} \mathrm{K}$ and $14^{\circ} \mathrm{K}$

Physical Review B 10 , 456-473 (1974)

COO-1198-1054

Y. M. Cheng, P. C. Allen, and D. Lazarus

Pressure Coefficient of Thermoelectric Power of P1atinum/P1atinum-10\%

Rhodium and Chrome1/Alumel Thermocouples

Applied Physics Letters (submitted to).

COO-1198-1103

Joan L. Mitchell and David Lazarus

Effect of Heterovalent Impurities Co-Diffusing with Monovalent Tracers in Ionic Crystals

Physical Review (submitted to)

CDO-1198-1114

M.S. Theses, Calendar Year 1974:

None

Ph.D. Theses, Calendar Year 1974:

Richard Spencer Hockett (D. Lazarus, Adviser)

Search for Magneto-F1icker Noise in Potassium

May 1974

C00-1198-1082

Joan Laverne Mitchel1 (D. Lazarus, Adviser)

Effect of Heterovalent Impurities Co-Diffusing with Monovalent Tracers in Ionic Crystals

October 1974

COO-1198-1115

Jonathan David Weiss (D. Lazarus, Adviser)

The Pressure Dependence of the Thermoelectric. Power of Sodium Between $5^{\circ} \mathrm{K}$ and $14^{\circ} \mathrm{K}$

February 1974

COO-1198-1024 
Properties of Noble Gas Crystals

Principal Investigator: Ralph O. Simmons, Ph.D.

Professor of Physics;

Head, Department of Physics

Supporting Agency: U. S. Atomlc Energy Commission

Senior Staff: Ralph O. Simmons, Professor

Donald Baer, Research Assoclate

Roy K. Crawford, Assistant Professor

Junfor Staff: Duane R. Aadsen, Research Assistant

Steve M. Heald, Research Assistant

Albert Macrander, Research Assistant

David H. Rieh1, Research Assistant

Object: Study of defect structure and lattice dynamics of noble gas and other molecular crystals. Noble gas crystals are model substances for testing theoretical 1deas about defect formation and mob1lity and about lattice dynamics, when the interatomic interactions are fairly well defined also from data on the liquid and gaseous phases. In crystalline helium such effects can be studied over. a broad range of densities. Quantum effects in diffusion are prominent. Defect characteristics are probed by $x$-ray scattering, macroscoplc observation, and by Raman scattering. Crystalline methanes offer the opportunity to study many phase transitions systematically.

Results, FY75: 1) Work on crystalline bcc ${ }^{3}$ He continued, to elucidate a) the volume dependence of the thermal vacancy content along the melting line and $b$ ) the nature of the excitations which appear to contribute a linear term to the heat capacity. 2) Lattice parameters of methane $\left(\mathrm{CH}_{4}\right)$ were studied over the range 2.5 to $86 \mathrm{~K}$, with special attention to the upper phase transition near $20.4 \mathrm{~K}$, which was proven to be first order, contrary to previous macroscopic and thermal evidence. 3) Two-phonon Raman spectra from solid argon have been studied from $14 \mathrm{~K}$ up to the melting curve, at different pressures up to 4 kbar. 4) Impurity-induced one-phonon Raman spectra from argonkrypton mixtures at different densities have yielded new information about phonon interactions in these anharmonic systems. 5) Apparatus to study thermal vacancy content isochorically in argon and krypton was completed.

Results Expected, FY76: We aim to characterize the thermal vacancy structure in the quantum crystals bcc He and $\mathrm{cph}$ He. In the dense solids argon and krypton, 1sochoric measurements of thermal vacancy content could resolve present lack of understanding of short range overlap forces in these and other crystals. Our phase transition experiments in the methanes will likely be concluded. 
Results Expected, FY77: Redirection of some project efforts can be expected into new studies of point and planar defects, and possibly of phase equilibration phenomena. High temperature materials are a prime target for planning.

Other. Work: Theoretical and experfmental work on noble gas crystals in the U. S. national laboratories and in U. S. unfversitles complements the present project but in no way duplicates any portion of 1 t. For example, laboratory work in the past several years Includes Brookhaven National Laboratory, Lawrence Berkeley Laboratory, Bel1 Laboratorles, and university work at Ames, Delaware, Case-Western Reserve, Florida, Rutgers, and Texas. Good communications are maintained to these groups and also workers abroad, at Darmstadt, Kharkov, Moscow, Munich, NRC Ottawa, Saclay, Sussex, and Toronto.

Publications, Calendar Year 1974:

R. Balzer and R. O. Simmons

Thermal Defects in bcc He Crystals Determined by X-ray Diffraction

Low Temperature Physics LT13 (Plenum Publishing Corp., New York, 1974)

Vo1. 2, pp. 115-119.

C 00-1198-929

R. K. Crawford

Hard Sphere Melting Model: Melting in Argon

Journal of Chemical Phys1cs 60, 2169-2174 (1974)

Co0-1198-991

R. K. Crawford

Melting, Vaporization and Sublimation

Rare Gas Solids; edited by M. L. Kleln and J. A. Venables

(Academic Press, New York, 1974), Vo1. I.

C00-1198-1007

V. M. Cheng, W. B. Daniels, and R. K. Crawford

Melting Parameters of Methane and Nitrogen from 0-10 Kilobars

Physical Review (submitted to)

Co0-1198-1111

M.S. Theses, Calendar Year 1974:

None

Ph.D. Theses, Calendar Year 1974:

William Harold Hardy II (R. O. Simmons, Adviser)

Debye-Waller Measurements in Silicon

May 1974

CoO-1198-1075 
Nuclear Magnetic Resonance in Solids

Principal Investigator: Charles P. Slichter, Ph.D.

Professor of Phystcs

Member, Center for Advanced Study

Supporting.Agency: U. S. Atomfc Energy Commisston

Senfor Staff: Charles P. Slfchter, Professor

Stephen F. Meyer, Research Assoctate

Junior Staff: Daniel Abbas, Research Assistant

Thomas J. Aton, Fellow

Stephen H. Couterié, Researchi Assistant

David M. Follstaedt, Research Assistant (Term 11/30/74)

James P. Long, Research Assistant

Howard E. Rhodes, Research Assistant

We are carrying out research in four general areas, and are planning a fifth.

\section{A) Magnetic Atoms In Non-magnet1c Metals}

Object: Since this research; involving study of the magnetization cloud near the tron group atoms present in low concentration in copper, Is described extenstvely in the "Signfftcant Results", we will not repeat it in detall.

We are studying two broad aspects: (a) The Kondo effect, a challenging many-body problem and (b) The general nature of the electronic structure of the magnetic atoms. The importance of the Kondo effect is that the theory is very similar to a number of other theoretical problems, such as the theory of the effect of electron-electron couplings on the optical and $x$-ray absorption of solids. Moreover, this is a case where many-body techniques are required, and this is in fact leading to major theoretical advances, the work of P. W. Anderson and K. Wilson on scaling methods. At the March 1974 meeting of the American Physical Society, James Boyce of our group spoke on our experiments and $\mathrm{K}$. Wilson of Cornell spoke on the theory in a session of Invited papers. Our expertment is free of many of the pitfalis of other experiments, especfally their sensitivity to small concentrations of clusters of magnetic atoms. Since we are using a spectroscoplc technlque, we can separate absorption IInes from isolated magnet1c atoms from those which form clusters. We have thus been able to clarify what was a highly confused experimental state.

The Importance of the work on the nature of the electronfc structure is that here again we are free of pftfalls of other methods; for example, of small prectpltates of the magnetic materials, and that the theory of the occurrence of magnetism in these materials is based on a set of parameters which have never prevtously been measured. We have hopes of deducing them from our measurements. 
Results, FY75: We are completing analysis of our experiment on the Kondo effect in CuFe in which we demonstrated that despite conjectures of other workers, there is no change in the shape of the magnetization cloud around the Fe atom when the sample is cooled from well above to well below the Kondo temperature.

We studied powders of CuSc and CuTi for the first time, and completed work on $\mathrm{CuV}$. For these systems which are difficult metallurgically, our work will provide some of the best measurements of the magnetic properties. We now have studied the entire iron group, Sc through $\mathrm{N} 1$, by NMR.

We have been able to detect the presence of small amounts of undissolved $\mathrm{V}$ in $\mathrm{CuV}$ alloys quenched from the melt. For CuSc we detect the presence of Sc atoms in two forms, one evidently isolated Sc atoms in $\mathrm{Cu}$, the other a compound (probably CuSc) but no Sc metal.

Our single crystal studies have enabled us to Identify the resonances of nuclei which are first neighbors of $N 1$ in CuN1, first and second neighbors to Co in CuCo, first, second, and third to Fe in CuFe, first and second nelghbors to Mn in CuMn.

We have found from the single crystals that there is a coupling of the magnetic atom to the nelghboring nuclei which has many features similar to the usual dipole-dipole coupling, but is several times larger. The term pseudodipolar coupling is ordinarily used for such a coupling. Present theories do not account for the size or assymetry of the coupling, but we are pursulng one which holds promise of explaining the results.

Results Expected, FY76: We will push the single crystal studies to enable us to Identify the crystallographic position relative to the impurfty of the nuclei associated with other resonance 1ines. We have a great deal of hope that this will prove feasible for CuMn, a system we are actively studying at present. Identiflcation of the shell of nuclet giving rise to a resonance is vital if one is to use our measurements to reconstruct the magnetization versus position of the magneti$z$ ation cloud.

We will then attempt to use our data to deduce the position and widths of the energy levels of the d-electrons of the iron group atoms in $\mathrm{Cu}$ and relate them to $P$. W. Anderson's theory.

Results Expected, FY77: We expect to complete our work on these systems in FY 76 .

\section{B) Charge Density Waves in Potassium}

Object: A few years ago, Overhauser made a proposal which sparked a large controversy. He proposed that under some circumstances the most stable arrangement of electrons in a metal was not the one usually assumed (uniform in space apart from a modulation which possesses the lattice perfodicity) but was rather non-uniform. The non-uniformity 
could be pictured as a wave of excess (or deficient) electron charge superposed on the normal uniform charge. He called the phenomena charge density waves. The controversial nature of his proposal can well be understood if one remembers that all previous theories of metals make as their starting assumption the uniformity of charge in space.

At first, Overhauser proposed that charge density waves might occur in the alkall metals, being responsible for certaln anomalous properties reported by experimenters. It now seems to be generally agreed that one has special requirements on the shape of the Fermi surface for the charge density waves to exist, requirements not met by the alkall metals, but satisfied by substances such as $\mathrm{TaS}_{2}$ (see below) in which recently charge density waves have been seen. ${ }^{2}$ For his stimulus in predicting this phenomenon, Overhauser is being awarded the Buckley Prize of the American Physlcal Soclety this year.

Results Expected, FY75 and Beyond: Several years ago, we declded to use nuclear magnetic resonance to test whether or not charge density waves existed in $\mathrm{K}$ metal. Our analysis showed that charge density waves could show up (1) In the Knight shift (2) In static quadrupole coupling (3) in spin lattice relaxation. We have completed these experiments and find that it is highly unllkely that there is a charge density wave (either static or a time-varying one) of the magnitude assumed by Overhauser for $K$. We are in the process of writing up the work for publication. We plan, however, to carry out studies of charge density waves in transition metal dichalcogonedes, systems where they are now known to occur as described below. It is interesting to note that their discovery (in $\mathrm{NbSe}_{2}$ by Gossard and Ehrenfreund) was made by nuclear magnetic resonance, the method we were using for potassium.

\section{C) A New Method for Electrical Conductivity Measurements}

Object: The conventional method of measuring electrical conductivity is the four probe method. In the last several years, the subject of conductivity measurements has interested many people because of the surprisingly high values reported by Heeger and his colleagues for the highly anisotropic organic electrical conductor TTF-TCNQ at temperatures near $80 \mathrm{~K}$. He suggested there might be a relationshlp of his results to superconductivity. Other workers proposed that his results were artifacts of poor or misaligned contacts in his four probe experiments: Stimulated by the potential importance of understanding the conductivity of compounds such as TTF-TCNO, we have devised a new method for measuring conductivity; one which will enable us to use a moving contact and thus to provide a self-check which we hope will assure that the results are valid.

The method involves putting the sample in a scanning electron microscope. Two contacts are attached to the sample. One 1s connected to ground. A voltmeter (actually a lock-in amplifier driving a chart recorder) is connected between the other and ground. Current is injected 
into the sample by the beam of the microscope. Modulation of the beam postition along the sample modulates the voltage measured by the voltmeter. The change in voltage. for a glven modulation amplitude and for a known current gives one the conductivity. Since one can move the beam continuously around on the crystal, one can check that the current flow patterns are well behaved, or whether, perhaps because of micro-cracks or poor contacts, they are not.

Results, FY75: We have verifled the method using graphite, and have carried out preliminary work on TTF-TCNQ. We are constructing a cold stage to enable us to go to the temperature region of the conductivity peak.

Results Expected, FY76: During this year and next we will explore the features of this technique as well as the properties of TTF-TCNQ, and related compounds.

Results Expected, FY77: We are working with a brand new technique which makes it very hard to predict what we should be doing in FY 77 . Even if we realize full success, we will face the cholce of continuing with this area of research, or deciding to consider a successful exploration of a new method as the best stopping point.

D) Nuclear Resonance Studies of Transition Metal-Chalcogonide Layer Compounds

Object: The atomic structure of materials such as $\mathrm{TaS}_{2}, \mathrm{NbSe}_{2}$ can be considered to be a stack of sandwiches, each sandwich consisting of a plane of transition metal atoms with a plane of chalcogonide atoms on either side.

These compounds have many interesting properties both scientifically and for possible practical applications. A variety of materials can be intercalated between the sandwich layers. Intercalation changes the superconducting transition temperature. In the section on "Significant Results", we describe Overhauser's prediction of a new kind of electronic phase for unfform solids, one in which the electronic density is not uniform, the so-called charge density waves. The transition meta1 chalcogonide compounds are found to exhiblt them. They were, in fact, first discovered by Gossard and Ehrenfreund using nuclear magnetic resonance. The phenomenon of charge density waves is one of the most startling and novel concepts to enter solld state physics, and provides a strong motive for studying these compounds.

We have been studying TaS intercalated with hydrogen by means of nuclear magnetic resonance of the protons. The general object is to learn why hydrogen causes the superconducting transition temperature to increase. Specifically, we hope to learn where the hydrogen goes in the lattice, about the ability of hydrogen to move in the lattice. It has been found by Wilson and colleagues at Bell Labs that $\mathrm{TaS}_{2}$ has density waves. The basic interest in this phenomena is described above for the case of potassium metal. The hydrogen atoms presumably interact 
with charge density waves and thus provide a tool for studying them. A broad question is whether or not the lattice instability plays an important role in the superconductivity of those compounds, as has been postulated for the A-15 compounds, the materials possessing the highest transition temperatures found to date. If 1 t does, one hopes to gain further insight into why some superconductors have hIgh transition temperatures.

Results, FY75: Our work began a year ago on the system $\mathrm{TaS}_{2}: \mathrm{H}$. We have found the proton NMR, and are studying its properties as a function of temperature and hydrogen concentration. As a by-product, in order to make samples, we have found that we can load hydrogen by heating the material under a pressure of hydrogen. We are establishing the relationship between gas pressure, temperature, and hydrogen content. We are measuring resonance line shape and spin-lattice relaxation. For some concentrations we find that the NMR line consists of several components--one broad, the other narrow. This suggests that several phases are coexisting. Our colleague, Professor McMillan, has recently completed a Landau theory describling both the static and dynamic properties of the charge density waves. These should be applicable to the NMR studies.

Results Expected, FY76: We hope to continue work on TaS :H to determine where the $\mathrm{H}$ atoms $\mathrm{sit}$ and what their interactions are with charge density waves. We wish to study charge density waves in other systems as a function of temperature to learn their structure, amplitude, and dynamic properties.

Results Expected, FY77: The wide variety of transition metal dichalcogines, the fact that the Fermi level can be adjusted by alloying, the fact that these systems possess two highly interesting properties (superconductivity and charge density waves) make them materials of very high intrinstc scientific interest, possibly even of practical importance. We wish to devote a major effort to their study in the next several years.

Other Work: In addftion to Professor McMillan who is working on the theory of these materials, Professor F. Brown wishes to study their Fermi surfaces by photoemission methods. We plan a close collaboration. We are fortunate in having $\mathrm{Dr}$. Steven Meyer as a post-doctoral research associate. He did his Ph.D. thesis on these materfals with Professor $T$. Geballe at Stanford, one of the foremost workers. Dr. Meyer came to Illinois to learn NMR, since that technique is not used in Dr. Geballe's laboratory. Brown, McMillan, and Meyer are also in contact with. Dr. Wilson's group at Bell Labs. We belleve, therefore, we are in good contact. With other workers and will not be Involved in duplication of effort.

Publications, Calendar Year 1974:

James B. Boyce, Thomas J. Aton, and Charles P. Slichter NMR Study of the Electron Spln Density Near Iron Group Atoms in Cu Proceedings of the Conference on Magnetism and Magnetic Materials 18, 252-256 (1974)

COO-1198-1020 
James B. Boyce and Charies P. Slichter

The Conduction Electron Spin Density Around Fe Impurities in $\mathrm{Cu}$ Above and Below $\mathrm{T}_{\mathrm{K}}$

Physica1 Review Letters 32 , 61-64 (1974)

COO-1198-1027

David V. Lang, Dav1d C. Lo, James B. Boyce, and C. P. S11chter

Measurements of Electron Spin Density Near Co Atoms in $\mathrm{Cu}$

Physical Review B9, 3077-3085 (1974)

COO-1198-1015

Lawrence R. Whalley and Charles P. Slichter

Electric Field Gradients in Copper-Nickel Alloys

Physical Review Bg, 3793-3796 (1974)

C00-1198-1032

James B. Boyce, Thomas Aton, Thomas Stakelon, and Charles P. Slichter Spin Polarization Near Iron Group Atoms in $\mathrm{Cu}$

Proceedings of the International Society of Magnetic Resonance, Bombay, India, January 1974 (to be published in the Journal of Pure and Applied Chemistry)

C00-1198-1056

Charles P. Slichter

Some Scient1fic Contributions of Herbert S. Gutowsky

Proceedings of the International Soclety of Magnet1c Resonance, Bombay, India, January 1974 (to be published in the Journal of Magnetic Resonance) COO-1198-1057

M.S. Theses; Calendar Year 1974:

None

Ph.D. Theses, Calendar Year 1974:

Thomas S. Stakelon (Charles P. Slichter, Adviser)

Nuclear Magnetic Resonance in Single Crystals of the Magnetic Alloys:

$\mathrm{CuFe}, \mathrm{CuCo}$, and CuNi

October 1974

COO-1198-1100

Lawrence Robert Whalley (Charles P. Slichter, Adv1ser)

Electric Fleld Gradients in Copper Alloys

February 1974

C00-1198-1134 
Physics of Refractory Materials

Principal Investigator: Wendell S. Willlams, Ph.D.

Professor of Physlcs, of Ceramlc Englneering, and of Bioengineering

Supporting Agency: U $\because$ S. Atomic Energy Commission

Senior Staff: Wende11 S. Will1ams, Professor*

Dwight R. Jennison, Research Assoclate

Junior Staff: Jim Bethin, Research Assistant (Ceramics)

Marvin W. Johnson, Research Assistant (Physics)

Michael Kolber, NIH Trainee (Physics)

Subhash Kulkarn1, Research Asslstant (Metallurgy) (Term 1/75)

Object: To characterize the thermal, mechanical and electrical properties

of selected ceramic materials, especially the transition-metal carbides, and to interpret these properties in terms of the electronic structure of the material. Recently the program has expanded to include studies of biological ceramics, bone and teeth. The general flavor of the program is interpretive: how can the extreme hardness of these materials, for example, be explained in terms of the detalls of the crystal bonding and information on dislocation propertles? The object is to put solfd state physics in the role of explaining the behavior of complex, real materials by using and extending the sophisticated and quantitative treatments of simple solids which represent $11 \mathrm{miting}$ cases. Such interpretation $1 \mathrm{~s}$ necessary for designing new refractory materials and understanding fallure of existing ones. These considerations are of considerable current importance, as new energy technologies require service under extreme conditions and appear to be materials-limited.

Results, FY75: (a) With the restricted Hartree-Fock, local orb1tals approach to the electronic structure of solids, we have constructed the local orbitals for TiC, calculated the charge density versus position in the crystal, and evaluated the overlap between $T i$ and $C 2 p$ orbitals. The presence of strong, partially polar, covalent bonding between $\mathrm{Ti}$ and $C$ is indicated. (b) High-temperature compression tests were initiated on samples of Co-bonded, polycrystalline carbldes for comparison with previous measurements, made on the same apparatus, on carbide single crystals. Preliminary results show that up to $1100^{\circ} \mathrm{C}$, the primary irreversible deformation is additional densification of the composite, whereas gross plastic deformation occurs in single crystals of the component carbides under similar conditions. (c) Dislocation velocity

\footnotetext{
*During FY 75 Professor Williams has been on leave of absence with the National Science Foundation, Division of Materials Research, Washington, D.C. However, the research has continued, being supervised by Professor Williams by monthly visits to the laboratory and via telephone and ma11, and by cooperation with several other faculty members.
} 
measurements on doped silicon single crystals using $x$-ray topography have been completed. For motion of both $60^{\circ}$ edge dislocations and screw dislocations, and for both $n$ - and p-type doping, the activation energies are lower than in intrinsic material by about half the band gap. (d) The study of large and mysterious plezoelectric signals in bent dry bone was extended to polymeric solids in hopes of finding a more uniform model material with the same property which would permit identification of the molecular origin of the effect. Of the several polymers tested, only nylon, which is hydrogen bonded, showed a plezoelectric response similar to bent bone. (e) Studies of the etching of dental enamel by HCl, EDTA and argon ions showed that only EDTA at neutral pH attacks the boundaries rather than the cores of the enamel prisms. A reported difference in the $\mathrm{Ca} / \mathrm{P}$ ratio between boundary and core by a few percent was confirmed with the electron probe.

Results Expected, FY76: (a) The local orbitals calculations Initiated in FY 75 for ceramic solids will be continued and used to generate energy-band structures, Fermi surfaces, Compton profiles, and Fourier transforms of charge densities for the family of $\mathrm{six}$ rocksalt structure transition-metal carbides. Comparison with experimental results will be made where available. (b) The compression tests on Co-bonded polycrystalline carbldes will be extended to higher temperatures to determine the mode of gross plastic deformation of cemented cutting-tool material. (c) The theoretical model for the influence of electronfcallyactive impurities on dislocation motion in covalent materials developed to interpret internal friction in S1 (FY 74) w111 be extended and applied to the results on dislocation velocities obtained in FY 75. (d) Measurements of the plezoelectric response of nylon in bending will be continued and the mechanism sought in the deformation of the hydrogen bond. (e) Information on the nature of bacterial acids thought to be related to tooth decay will be obtained and a relation to the etching results with simple acids will be sought. (f) a new project in surface hardness will be launched: the goal will be to examine critically the reported environment sensitivity of the hardness of ionlc/covalent materlals--particularly the suggested relationship between zeta potential and hardness--and relate these findings, if real, to our models for the relationship between electronic states and dislocation kink nucleation and migration.

(g) Another new project will also be launched: links will be sought between the electronic structure of ceramics, as calculated by the local orbitals method, applied to clusters of atoms, and the defect properties of these nonstoichiometric materials. (h) the exploration of possible catalytic activity of cubic carbides, not containing tungsten, is another likely new direction. As with $P t$ and WC, nloblum carblde has a high density of states at the Fermi level. Theoretical studies of local orbital configurations at the surface in these and other catalysts will be included.

Results Expected, FY77: The directions outlined in previous years should converge to give a substantial boost to our fundamental understanding of the mechanical, transport and catalytic properties of very hard ceramics. 
The ab initio calculations for both clusters and infinite crystals will indicate the location and character of the bonds and the changes in these produced by defects and surfaces. Experimental results using studies of macroscopic plastlc flow and individual dislocations will be related, through models of dislocation-lattice and dislocationelectron Interactions, to intrinsic and environment-sensitive hardness. Catalytic activity will be given as much interpretation as can be extracted from a systematlc study of catalysts and non-catalysts in the same family of solids (transition-metal carbldes). For mechanical studies, the materials w11l be expanded to include S1C and SIN. Other grant support will be obtalned for the work on biological materials.

Other Work: (1) A strong interaction with Professor Kunz's theoretical program of calculating the electronic structure of solids has been established via Dr. Jennison, a Research Assoclate. (2) Increasing interaction with Professor Granato is expected in the area of dislocationelectron problems. (3) In connection with the studies of individual dislocations in carbides, interactions with Professor Fraser and the transmission electron microscope will be developed. (4) Extensive use of the MRL central facilities, a feature of this program from the beginning, will be continued. (5) In collaboration with ORNL, a high-density grade of graphite which they prepare is under test as an orthopedic 1mplant through the College of Veterfnary Medicine. (6) Also through the College of Veterinary Medicine, a project is continuing on electrically-stimulated bone growth. Results to date, which have recelved wide public notice, suggest that bone degeneration produced by disuse (osteoporosis) can be prevented by the introduction of electrical signals to substitute for the plezoelectric signals produced by bone in normal activity. (7) In collaboration with the Department of Physiology and Biophysics (Professor Jakobsson), we are exploring problem areas in the mathematical modeling of cell membrane function.

Publications, Calendar Year 1974:

Wendell S. Williams

Sources of Plezoelectricity in Tendon and Bone

Critical Reviews of Bloengineering 2 , 95-118 (1974)

C00-1198-1013

W. S. Williams, L. Breger, and M. Johnson

Ceramic Models for Study of Plezoelectric1ty in Organic Sollds

Journal of the American Ceramic Soclety (submitted to).

COO-1198-1112

Wendell S. Willlams and Lance Breger

Piezoelectricity in Tendon and Bone

Journal of Biomechanics (submitted to)

C00-1198-1006 
M.S. Theses, Calendar Year 1974:

Danfel Sutherland Petty (Wendell S. Willlams, Adviser)

Investigation of Preferential Etch Patterns Created In Human Dental

Enamel During Acid Attack

October 1974

COO-1198-1142

Ph.D. Theses, Calendar Year 1974:

Lance Harris Breger (Wendell S. Williams, Adviser)

Piezoelectric Response of Bone and Tendon Subjected to Inhomogeneous Stress October 1974

C00-1198-1099

Alvin Phlliip Gerk (Wendell S. W1lliams, Adviser)

Internal Friction in Intrinsic and n-Type Germantum and Stlicon

February 1974

C00-1198-1029 
NT-03-02-04-0 Particle Solld Interactions

Radiation Damage In Solids

Principal Investigator: James S. Koehler, Ph.D.

Professor of Physics

Supporting Agency: U. S. Atomic Energy Commission

Senior Staff: James S. Koehler, Professor

Wolfram Hertz, Research Associate

Junior Staff: Robert C. Birtcher, Research Assistant (until 3/1/75)

Walter S. Knodle, Research Assistant

Thomas Kriisa, Research Assistant

Maria A. Menendez, Research Assistant

Object: We wish to determine the geometrical structure, the migration and formation energies, and the physical property changes associated with the presence of defects in solids resulting from irradiation. Materials problems in reactors cannot be eliminated without such knowledge.

Results, FY75: During the past year we have: (1) Shown that Stage I annealing of lead is analogous to $S$ tage $I$ in copper except that the annealing occurs at much lower temperature $\left(\mathrm{T}_{1 \mathrm{D}}(\mathrm{Pb})=4.1 \mathrm{~K}, \mathrm{~T}{ }_{1 \mathrm{D}}(\mathrm{Cu})\right.$

$=37 \mathrm{~K})$. Gold remains anomalous. (2) Given $\mathrm{a}$ theory of steady

state void growth in irradiated pure metals and in alloys. This

paper has been accepted for publication in the Journal of Applied

Physics.

We plan to electron irradiate gold at $0.5 \mathrm{~K}$ and hope to stop. Interstitial migration. We also plan to Irradiate silver at $100 \mathrm{~K}$ in ultra high vacuum and study. the annealing near room temperature. We believe that the anomalous results which we found previously were associated with gaseous impurttles.

Results Expected, FY76: We plan to measure length changes during irradiation at high temperature. We believe that swelling can be reduced if certain impurities are present. We also plan to irradiate certain hexagonal metals at $3 \mathrm{~K}$. The geometrical nature of the interstitial is as yet unknown in any hexagonal metal.

Results Expected, FY77: We are at present making theoretical calculations concerning transient defects. We hope to devise experiments to detect transient defects. We hope to show that they are 1mportant for phase changes.

Other Work: We have done cooperative research with Dr. Y. Lwin of Western Illinois University and with Mr. E. Ryan and Dr. J. J. Jackson of the Argonne National Laboratory. (See Physlcal Review Letters 33, 899 (1974) and Bulletin of The American Physical Society 20, Denver Meeting, to appear 1975.) 
Publications, Calendar Year 1974:

R. C. Birtcher, Y. LWIn, and J. S. Koehler

Is ochronal Annealing of Pure Lead Electron Irradlated at $1.5^{\circ} \mathrm{K}$

Physical Revlew Letters 33, 899-900 (1974)

C00-1198-1096

J. Koehler

Decrease in the Void Growth Rate by Interstitial Trapping

Journal of Applied Phystcs (submitted to)

C0O-1198-1108

M.S. Theses, Calendar Year 1974:

None

Ph.D. Theses, Calendar Year 1974:

None 


\title{
AEC PERSONNEL
}

\author{
Senior Staff
}

Car1 J. Altstetter, Professor, Department of Metallurgy and Mining Engineering, Acting Head of Department

Donald Baer, Research Associate, Department of Physlcs

Paul A. Beck, Professor, Department of Metallurgy and Mining Engineering

John P. Bensel, Research Assoclate, Department of Physics

Howard K. Birnbaum, Professor, Department of Metallurgy and Mining Engineering

C. Gregory Chen, Research Associate, Department of Metallurgy and Mining Engineering

Roy K. Crawford, Assistant Professor, Department of Physics

Harry G. Drickamer, Professor, Department of Chemical Engineering and of Physical Chemistry

Hamlsh L. Fraser, Assistant Professor, Department of Metallurgy and Mining Engineering

Arthur L. Friedberg, Professor, Department of Ceramic Englneering; Head of Department

Andrew V. Granato, Professor, Department of Physics

Wolfram Hertz, Research Assoclate, Department of Physics

Nick Holonyak, Jr., Professor, Department of Electrlcal Engineering

Dwight R. Jennison, Research Associate, Department of Physics

Jiri Jonas, Professor, Department of Chemistry

James S. Koehler, Professor, Department of Physics

David Lazarus, Professor, Department of Phýsics

John W. Linowski, Research Associate, Department of Chemistry

Robert J. Maurer, Professor, Department of Physics; Director, Materials Research Laboratory

Marvin Metzger, Professor, Department of Metallurgy and Mining Engineering

Stephen F. Meyer, Research Associate, Department of Physics

Kazuhiro Otsuka, Visiting Research Associate Professor, Department of Metallurgy and Mining Englneering

Edwin L. Pollock, IBM Postdoc Fellow and Research Assoclate, Department of Metallurgy and Mining and of Physics

E. Neville Pugh, Professor, Department of Metallurgy and Mining Engineering

Theodore J. Rowland, Professor, Department of Metallurgy and Mining Engineering

Ricardo B. Schwarz, Visiting Assistant Professor, Department of Physics

Ralph 0. Simmons, Professor, Department of Physics; Head of Department

Charles.P. Slichter, Professor, Department of Physics

C. Marvin Wayman, Professor, Department of Metallurgy and Mining Engineering

Charles A. Wert, Professor, Department of Metallurgy and Mining Engineering; Head of Department

Wendell S. Williams, Professor, Department of Physics, of Ceramic Engineering, and of Bioengineering 
Junfor Staff

Duane R. Aadsen, Research Assistant, Department of Physlcs

Daniel Abbas, Research Assistant, Department of Physics

Paul C. Allen, Research Assistant, Department of Physlcs

Thomas J. Aton, Fellow, Department of Physics

Joseph J. Au, Research Assistant, Department of Metallurgy and Mining

Terrell D. Berker, Research Assistant, Department of Physlcs

Jim Bethin, Research Assistant, Department of Ceramics

Prabir R. Bhowal, Research Assistant, Department of Metallurgy and Mining

Kevin Bieg, UI Fellow, Department of Chemistry

Patricla A. Birnbaum, Graduate Fellow, Department of Metallurgy and Mining

Michael P. Cassidy, Research Assistant, Department of Metallurgy and Mining

$S$. Chakravorty, Research Assistant, Department of Metallurgy and Mining

Stephen H. Couterie, Research Assistant; Department of Physics

T. DeFries, Graduate Student, Department of Chemistry

William D. Drotning, Research Assistant, Department of Physics

Gennghmun Eng, Research Assistant, Department of Physics

Jun Ichi Fujita, Research Assistant, Department of Metallurgy and Mining

Michael Fury, Research Assistant, Department of Chemistry

Steve M. Heald, Research Assistant, Department of Physlcs

Eric Hockert, UI Fellow, Department of Chemistry

John W. Hook III, Teaching Assistant, Department of Chemfstry

Gary L. House, Research Assistant, Department of Chemistry

Scott E. Hughes, Research Assistant, Department of Metallurgy and Mining

Randa11 D. Isaac, Research Assistant, Department of Physics

Mark S. Jackson, Research Assistant, Department of Physics

David L. Johnson, Research Assistant, Department of Physics

Marvin W. Johnson, Research Assistant, Department of Physics

Myung-Hwan KIm, Research Assistant, Department of Metallurgy and Mining

David I. Klick, Research Assistant, Department of Physics

Walter S. Knodle, Research Assistant, Department of Physics

Gerhardus H. Koch, Research Assistant, Department of Metallurgy and Mining

Michael Kolber, NIH Trainee, Department of Physics

Thomas Kriisa, Research Assistant, Department of Physlcs

Lance C. Labun, Research Assistant, Department of Metallurgy and Mining

Patrick M. Lenahan, Research Assistant, Department of Metallurgy and Mining

Robert W. Levis, Research Assistant, Department of Metallurgy and Mining

James P. Long, Research Assistant, Department of Physics

Albert Macrander, Research Asisistant, Department of Physlcs

Gerald R. Matusiewicz; Research Assistant, Department of Metallurgy and Mining

Marfa A. Menendez, Research Assistant, Department of Physlcs

Dean J. Mitchell, Research Assistant, Department of Chemistry

J. Lawrence Nelson, Research Assistant, Department of Metallurgy and Mining

David B. Poker, Research Assistant, Department of Physics

Arthur E. Pontau, Research Assistant, Department of Physics

Howard E. Rhodes, Research Assistant, Department of Physics

David H. Rieh1, Research Assistant, Department of Physics

Robert S. Shalvoy, Research Assistant, Department of Metallurgy and Mining

Robert D. Shul1, Research Assistant, Department of Metallurgy and Mining 
Gary L. Steckel, Research Assistant, Department of Metallurgy and Mining Peter F. Tortorelli, Research Assistant, Department of Metallurgy and Mining Randal W. Tustison, Research Assistant, Department of Metallurgy and Mining Craig E. Tyner, NSF Fellow, Department of Chemistry

Theodore R. Wilken, Research Assistant, Department of Metallurgy and Mining Doug Wilson, NSF Fellow, Department of Chemistry

Nestor J. Zaluzec, Research Assistant, Department of Metallurgy and Mining Philip E. Zapp, Research Assistant, Department of Metallurgy and Mining 


\section{Professional Staff}

Materials Research Laboratory

Judith A. Baker, B.A., Assistant Research Chemlst (AEC-NSF)

Richard J. Blattner, M.S., Research Chemlst (AEC-NSF)

Charles A. Evans, Jr., Ph.D., Sentor Research Chemlst (AEC, NSF, and ARPA)

Russell F. Marshal1, Ph.D., Research Englneer

Virginia C. Metze, Research Computer Programmer

Connie Silber, B.A., Assistant Research Chemist (AEC-NSF)

Ian D. Ward, Research Metallurgist (AEC)

Peter Williams, Ph.D., Research Chemist (AEC-NSF)

John B. Woodhouse, B.A., Research Microprobe Analyst (AEC-NSF-ARPA) 


\section{PUBLICATIONS \\ (Calendar Year 1974)}

There were 49 AEC-supported publications for the Calendar Year 1974. In addition, there were 20 papers in process of publication.

NT-03-01-01-0 Structure of Materials

C00-1198-1113 G. P. Asselin and C. M. Wayman, "Nucleation and Growth of Tungsten Films Evaporated on $\mathrm{NaCl}, "$ physica status solidi (a) 24, 675-690.(1974).

C00-1198-1041 D. J. Chakrabart1, "Effect of Atomic Ordering on the Magnetic Properties of $\mathrm{Pd}_{3} \mathrm{Mn}$ and of Some More Dilute Pd-Mn Alloys," International Journal of Magnetism $\underline{6}$, 305-311 (1974).

C00-1198-1059 I. Cornelis, R. Oshima, H. C. Tong, and C. M. Wayman, "Direct Observations of Pretransformation Lattice Instabilities," Scripta Metallurgica $\underline{8}, 133-144$ (1974).

C00-1198-1000 I. Cornelis and C. M. Wayman, "Phase Transformations in Metastable $\beta^{\prime}$ CuZn Alloys I: Martensitic, Transformations," Acta Metallurgica 22, 291-300 (1974).

C00-1198-1001 I. Cornelis and C. M. Wayman, "Phase Transformations in Metastable $\beta^{\prime}$ CuZn Alloys II: Isothermal Transformations," Acta Metallurgica 22, 301-311 (1974).

C00-1198-1101 T. P. Darby and C. M. Wayman, "Anomalous Diffraction Doublet from Gold Films on. Graphite Substrates," Philosophical Magazine 30, 1171-1175 (1974).

C00-1198-1133 T. P. Darby and C. M. Wayman, "Growth of Gold Films on Air- and Vacuum-Cleaved Molybdenite," physica status solidi (a) 25, 585-590 (1974).

C00-1198-854 B. de Mayo, "Magnetism in Gold-Iron Alloys Below 14 at.\% Fe," Journal of the Physics. and Chemistry of Solids 35 , 1525 (1974).

C00-1198-1026 S. Mishra, E. J. Hayes, R. Tustison, and P. A. Beck, "Magnetism in $\mathrm{Ni}-\mathrm{Cu}$ and $\mathrm{Co}-\mathrm{Re}$ Solid Solutions," Journal de Physique 35, C4-194 (1974). 


\begin{abstract}
C00-1198-1021 H. C. Tong and C. M. Wayman, "Characteristic Temperatures and Other Properties of Thermoelastic Martensites," Acta Metallurgica 22, 887-896 (1974).

C00-1198-1067 H. C. Tong and C. M. Wayman, "Direct Evidence of Pretransformation Lattice Instabilities," Physical Review Letters 32 , 1185-1188 (1974).

C00-1198-1061 H. C. Tong and C. M. Wayman, "A Simplified Calorimeter for Determining Latent Heats of Martensitic Transformations at Low Temperatures," Metallurgica Transactions $\underline{5}, 144.5$ (1974).

C00-1198-1022 H. C. Tong and C. M. Wayman, "Some Stress-TemperatureEnergy Relationships for Thermoelastic Martensitic Transformations," Scripta Metallurgica 8, 93-100 (1974).

C00-1198-1136 A. Mukhopadhyay, R. D. Shul1, and P. A. Beck, "Relaxation and Magnetic Clusters in Mictomagnetic Cu-Mn Alloys," Physical Review. B (submitted to).

C00-1198-1116 R. D. Shu11 and Paul A. Beck, "Mictomagnetic to Ferromagnetic Transition in $\mathrm{Cr}-\mathrm{Fe}$ Alloys," Proceedings of the 20 th Conference on Magnetism and Magnetic Materials, San Francisco, 1974 (submitted to).

C00-1198-1102 H. C. Tong and C. M. Wayman, "Thermodynamic Considerations of 'Solid State. Engines' Based on Thermoelastic Martensitic Transformations and the Shape Memory Effect," Metallurgical Transactions (submitted to).

c00-1198-1064 H. C. Tong and C. M. Wayman, "Thermodynamics of Thermoelastic Martensitic Transformations," Acta Metallurgica (submitted to).
\end{abstract}


NT-03-01-02-0 Mechanical Properties

C00-1198-1079 H. Y. Chang, R. K. Viswanadham, and C. A. Wert, "Age Hardening in the $\mathrm{V}-\mathrm{C}$ and $\mathrm{Nb}-\mathrm{C}$ Systems," Metallurgical Transactions $\underline{5}$, 1907-1917 (1974).

C00-1198-1078 H. Y. Chang and C. A. Wert, "Precipitation of Carbides in Deformed Vanadium," Metallurglcal Transactions $\underline{5}$, 1671-1676 (1974).

C00-1198-990 B. Ganguly, C. Wert, and J. Woodhouse, "Microchemistry of Copper-Infiltered Iron Powder," International Journal of Powder Metallurgy 10, 87-99 (1974).

C00-1198-1095 J. E. Greene, J. Woodhouse, and M. Pestes, "A Technique for Detecting Critical Loads in the Scratch Test for Thin Film Adhesion," The Review of Scientific Instruments 45, 747-749 (1974). Also supported by JSEP DAAB-07-72-C-0259.

C00-1198-1105

G. Matusiewicz, R. Booker, J. Keiser, and H. K. Birnbaum, "On Gorsky Measurements of Hydrogen Diffusion in Niobium," Scripta Metallurgica 8 , 1419-1426 (1974).

C00-1198-1076 G. J. Sellers, A. C. Anderson, and H. K. Birnbaum, "The Anomalous Heat Capacities of Niobium and Tantalum Below $1 \mathrm{~K}, "$ Physical Review B10, 2771-2776 (1974). Also supported by the National Science Foundation.

C00-1198-968 R. K. Viswanadham and C. A. Wert, "Precipitation from Super-Saturated Nb-C Solid Solutions," Metallurgical Transactions $\underline{5}$, 123-126 (1974).

C00-1198-1002

J. B. Woodhouse, A. L. A. Fields, and I. A. Bucklow, "X-ray Mass Absorption Coefficients for Gold, Lead and Bismuth in the Range $1 \AA$ to $10 \AA, "$ Journal of Physics D: Applied Physics 7 , 1483-1489 (1974).

C00-1198-858 J. Zahavi and M. Metzger, "Breakdown of Films and Initiation of Pits on Aluminum During Anodizing, Localized Corrosion," National Association of Corrosion Engineers 3 , 547-555 (1974). Also supported by the U. S. Army Research Office (Durham). 
C00-1198-1010 J. Zahavi and M. Metzger, "Effect of Chloride on Growth of an Anodic Film," Journal of the Electrochemical Society 121, 268-279 (1974). Also supported by U. S. Army Research office (Durham).

C00-1198-1094

Nestor J. Zaluzec and Hamish L. Fraser, "The Origin of Dislocation with $\underline{b}=\langle 110\rangle$ in Single Crystals of $B-N i A 1$ Compressed Along <001> at Elevated Temperatures," Scripta Metallurgica 8, 1049-1054 (1974).

C00-1198-1107 D. G. Chakrapani and E. N. Pugh, "On the Fractography of Transgranular Stress-Corrosion Failures in a Mg-Al Alloy," Corrosion (submitted to).

C00-1198-1104 D. G. Chakrapani and E. N. Pugh, "The Transgranular SCC of a Mg-A1 Alloy: Crystallographic, Fractographic and Acoustic-Emission Studies," Metallurgical Transactions (submitted to).

C00-1198-1106 R. F. Mattas and H. K. Birnbaum, "Isotope Effects on the Motion of $\mathrm{O}-\mathrm{H}$ Clusters in $\mathrm{Nb}, "$ Acta Metallurgica (submitted to).

NT-03-01-03-0 Physical Properties

None

NT-03-02-04-0 Particle Solid Interactions

C00-1198-1096 R. C. Birtcher, Y. Lwin, and J. S. Koehler, "Isochronal Annealing of Pure Lead Electron Irradiated at $1.5^{\circ} \mathrm{K}, "$ Physical Review Letters 33, 899-900 (1974).

C00-1198-1108 .J. Koehler, "Decrease in the Void Growth Rate by Interstitial Trapping," Journal of Applied Physics (submitted to). 


\section{NT-03-02-02-0 Experimental Research}

C00-1198-929 R. Balzer and R. O. Simmons, "Thermal Defects in bcc ${ }^{3}$ He Crystals Determined by X-ray Diffraction," Low Temperature Physics LT13 (Plenum Publishing Corp., N.Y., 1974) Vo1. 2, pp. 115-119.

C00-1198-1020 James B. Boyce, Thomas J. Aton, and Charles P. Slichter, "NMR Study of the Electron Spin Density Near Iron Group Atoms in $\mathrm{Cu}, "$ Proceedings of the Conference on Magnetism and Magnetic Materials 18, 252-256 (1974).

C00-1198-1027 James B. Boyce and Charles P. Slichter, "The Conduction Electron Spin Density Around Fe Impurities in Cu Above and Below $\mathrm{T}_{\mathrm{K}}$," Physical Review Letters $\underline{32}$, 61-64 (1974).

C00-1198-991 R. K. Crawford, "Hard Sphere Melting Model: Melting in. Argon," Journal of Chemical Physics 60 , 2169-2174 (1974).

C00-1198-1007 R. K. Crawford, "Melting, Vaporization and Sublimation," Rare Gas Solids, edited by M. L. Klein and J. A. Venables (Academic Press, N.Y., 1974) Vol. I.

C00-1198-976

H. G. Drickamer, "Electronic Transitions in Transition Metal Compounds at High Pressure," Angewandte Chemie 13, 39-47 (1974).

C00-1198-1080 D. L. Fanselow and H. G. Drickamer, "High Pressure Studies of the Electronic Behavior of Bianthrones," Journal of Chemical Physics 61, 4567-74 (1974).

C00-1198-906 E. R. Fuller, Jr., A. V. Granato, J. Holder, and E. R. Naimon, "Ultrasonic Studies of the Properties of Solids," Solid State Volume of METHODS OF EXPERIMENTAL PHYSICS, edited. by R. V. Coleman (1974) p. 371. Also supported by the National Science Foundation and the Advanced Research Projects Agency.

C00-1198-1065 E. R. Fuller, Jr., and W. F. Weston, "Relation Between Elastic-Constant Tensors of Hexagonal and Cubic Structures," Journal of Applied Physics 45, 3772-3776 (1974).

C00-1198-1028 N. A. Halasa, G. DePasquali, and H. G. Drickamer, "High Pressure Studies of Ferrites," Physical Review B10, 154-164 (1974). 
C00-1198-1084

$.600-1198-1034$

C00-1198-1038

C00-1198-1015

C00-1198-1062

C00-1198-1074

C00-1198-1072

C00-1198-1097

C00-1198-1071

C00-1198-1035
R. S. Hockett and David Lazarus, "Search for MagnetoFlicker Noise in K," Physical Review B10, 4100-4111 (1974).

J. Holder, A. V. Granato, and L. E. Rehn, "Experimental Evidence for Split Interstitials in Copper," Physical Review Letters 32, 1054-1057 (1974). Also supported by the National Science Foundation.

J. Holder, A. V. Grànato, and L. E. Rehn, "Effects of Self-Interstitials and Close Pairs on the Elastic Constants of Copper," Physical Review B10, 363-375 (1974). Also supported by the National Science Foundation.

David V. Lang, David C. Lo. James B. Boyce, and C. P. Slichter, "Measurements of Electron Spin Density Near Co Atoms in Cu," Physical Review B9, 3077-3085 (1974).

S. H. Moon and H. G. Drickamer, "The Effect of Pressure on Hydrogen Bonds in Organic Solids," Chemical Physics 61, 48-54 (1974).

B. Y. Okamoto and H. G. Drickamer, "The Evaluation of Configuration Coordinate Parameters from High. Pressure Optical Data I: Phenanthrene, Anthracene and Tetracene," Journal of Chemical Physics 61, 2870-2877 (1974).

B. Y. Okamoto and H. G. Drickamer, "The Evaluation of Configuration Coordinate Parameters from High Pressure Optical Data II: Purine and Pyrimidine Bases and Nucleosides," Journal of Chemical Physics 61, 28782882 (1974).

B. Y. Okamoto and H. G. Drickamer, "High Pressure Studies of Solvent Effects on Anthracene Spectra," Proceedings of the National Academy of Sciences 71, 4757-4759 (1974).

B. Y. Okamoto, W. D. Drotning, and H. G. Drickamer, "The Evaluation of Configuration Coordinate Parameters from High Pressure Absorption and Luminescence Data," Proceedings of the National Academy of Sciences 71 , 2671-2674 (1974).

L. E. Rehn, J. Holder, A. V. Granato, R. R. Coleman, and F. W. Young, Jr., "Effects of Thermal Neutron Irradiation on the Elastic Constants of Copper," Physical Review BiO, 349-362 (1974). Also supported by the National Science Foundation. 
C00-1198-1033

Gregorio Weber, Fumio Tanaka, Byron Y: Okamoto, and H. G. Drickamer, "The Effect of Pressure on the Molecular Complex of Isoalloxazine and Adenine," Proceedings of the National Academy of Sciences 71 , 1264-1266 (1974).

C00-1198-1054 Jonathan D. Weiss and D. Lazarus, "Pressure Dependence of the Thermoelectric Power of Sodium Between $5^{\circ} \mathrm{K}$ and $14^{\circ} \mathrm{K}, "$ Physical Review B10, 456-473 (1974).

C00-1198-1032 Lawrence R. Whalley and Charles P. Slichter, "Electric Field Gradients in Copper-Nickel Alloys," Physical Review B.9, 3793-3796 (1974).

C00-1198-1013 Wendell S. Williams, "Sources of Piezoelectricity in Tendon and Bone," Critical Reviews of Bioengineering 2, 95-118 (1974).

C00-1198-1056 James B. Boyce, Thomas Aton, Thomas Stakelon, and Charles P. Slichter, "Spin Polarization Near Iron Group Atoms in $\mathrm{Cu}$," Journal of Pure and Applied Chemistry (submitted to).

C00-1198-1103 Y. M. Cheng, P. C. Allen, and D. Lazarus, "Pressure Coefficient of Thermoelectric Power of Platinum/Platinum10\% Rhodium and Chromel/Alume1 Thermocouples," Applied Physics Letters (submitted to).

C00-1198-1111 V. M. Cheng, W. B. Daniels, and R. K. Crawford, "Melting Parameters of Methane and Nitrogen from 0-10 Kilobars," Physical Review (submitted to).

C00-1198-1083 H. G. Drickamer, "The Effect of Pressure on the Electronic States of Organic Solids," Proceedings of the International Conference on Organic Synthesis, Belgium (submitted to).

C00-1198-1092 J. A. Garber and A. V. Granato, "Fourth-Order Elastic Constants and the Temperature Dependence of SecondOrder Elastic Constants in Cubic Materials," Physical Review (submitted to).

C00-1198-1091 J. A. Garber and A. V. Granato, "Theory of the Temperature Dependence on Second-Order Elastic Constants in Cubic Materials," Physical Review (submitted to). 
C00-1198-1114

Joan L. Mitche11 and David Lazarus, "Effect of Heterovalent Impurities Co-Diffusing with Monovalent Tracers in Ionic Crystals," Physical. Review (submitted to).

C00-1198-1017 L. A. Schwalbe, "Equilibrium Vacancy. Concentration Measurements in Solid Argon," Physical Review (submitted to).

C00-1198-1057 Charles P. Slichter, "Some Scientific Contributions of Herbert S. Gutowsky," Journal of Magnetic Resonance (submit.ted to).

C00-1198-1016 K. D. Swartz, W. Bensch, and A. V. Granato, "The Second, Third, and Fourth Order Elastic Constants of Beta Brass," Physical Review (submitted to).

C00-1198-1006 Wendell S. Williams and Lance Breger, "Piezoelectricity in Tendon and Bone," Journal of Biomechanics (submitted to).

C00-1198-1112 W. S. Williams, L. Breger, and M. Johnson, "Ceramic Models for Study of Piezoelectricity in Organic Solids," Journal of the American Ceramic Society (submitted to). 
Ph.D. DISSERTATIONS

(Calendar Year 1974)

Sixteen Ph.D. theses were completed and degrees granted with AEC support for the Calendar Year 1974.

Lance Harris Breger (W. S. Williams, Adviser), "Piezoelectric Response of Bone and Tendon Subjected to Inhomogeneous Stress," October 1974.

Thomas P. Darby (C. M. Wayman, Adviser), "Nucleation and Growth of Gold Thin Films Vapor Deposited on Single Crystal Graphite Substrates," May 1974.

Dan L. Fanselow (H. G. Drickamer, Adviser), "The Effect of High Pressure on the Series of Photochromic, Thermochromic, and Piezochromic and Bianthrones," October 1974.

Alvin Phillip Gerk (W. S. Williams, Adviser), "Internal Friction in Intrinsic and n-Type Germanium and Silicon," February 1974.

Nicholas Allen Halasa (H. G. Drickamer, Adviser), "Hyperfine Interactions in Ferrites and Orthoferrites at High Pressure," February 1974.

William Harold Hardy, II (R. O. Simmons, Adviser), "Debye-Waller Measurements in Silicon," May 1974.

Richard Spencer Hockett (D. Lazarus, Adviser), "Search for Magneto-Flicker Noise in Potassium," May 1974.

Philippe Lecocq (C. A. Wert, Adviser), "The Solubility of Hydrogen in Tantalum," October 1974.

Sang Heup Moon (H. G. Drickamer, Adviser), "High Pressure Studies on Hydrogen Bonding in Solids,". May 1974.

Richard Francis Mattas (H. K. Birnbaum, Adviser), "Low Temperature Internal Friction in the Niobium-Hydrogen and Niobium-Oxygen-Hydrogen Systems," May 1974.

Joan Laverne Mitche11 (D. Lazarus, Adviser), "Effect of Heterovalent Impurities Co-Diffusing with Monovalent Tracers in Ionic Crystals," October 1974.

Lynn Eduard Rehn (J. Holder, de facto Adviser and A. V. Granato, de jure Adviser), "Contributions from Point Defects to the Elastic Constants. of Copper," February 1974. 
Thomas Stanley Stakelon (Charles P. Slichter, Adviser), "Nuclear Magnetic Resonance in Single Crystals at the Magnetic Alloys: CuFe, CuCo, and CuNi," October 1974.

Jonathan David Weiss (D. Lazarus, Adviser), "The Pressure Dependence of the Thermoelectric Power of Sodium Between $5^{\circ} \mathrm{K}$ and $14^{\circ} \mathrm{K}, "$ February 1974.

Lawrence Robert Whalley (Charles P. Slichter, Adviser), "Electric Field Gradients in Copper Alloys," February 1974.

Andrew Chien-Chong Yen (T. J. Rowland, Adviser), "A Study of Precipitation in Copper +13 Atomic Percent Beryllium by Nuclear Magnetic Resonance and Field Ion Microscopy," June 1974. 


\section{M.S. DISSERTATIONS \\ (Calendar Year 1974)}

Seven M.S. theses were completed and degrees granted with AEC support for the Calendar Year 1974.

Gillis P. Asselin (C. M. Wayman, Adviser), "The Nucleation and Growth of Tungsten Thin Films Vapor Deposited on Vacuum-Cleaved Rock Salt Substrates," August 1973 (omitted from last year's report).

Yue-Kong Au (C. M. Wayman, Adviser), "Some Electrical Properties of Amorphous Germanium, Indium Antimonide and Gallium Antimonide Films," August 1974 .

Christian Paul Fluhr (C. A. Wert, Adviser), "An Electron Microscopy Study of Carbide Precipitation in a Vanadium-Titanium Alloy," May 1974.

Howard Gabel (E. N. Pugh, Adviser), "An Electron Microprobe Study of the Composition of Tarnish Films on Copper-Zinc, Copper-Aluminum, and Copper-Nickel Alloys," January 1974.

Daniel Sutherland Petty (W. S. Williams, Adviser), "Investigation of Preferential Etch Patterns Created in Human Dental Enamel During Acid Attack," October 1974.

Terrence Alan Schroeder (C. M. Wayman, Adviser), "Shape Memory Behavior and Mechanical Characteristics of Some Copper Zinc Alloys," June 1974.

D. L. Woracek (H. G. Drickamer, Adviser), "Effects of Pressure on Alkali Halides Doped with Lead (II)," June 1974. 
